\title{
Mesoscale Characterization of Coupled Hydromechanical Behavior of a Fractured Porous Slope in Response to Free Water-Surface Movement
}

\author{
Y. Guglielmi ${ }^{a^{*}}$, F. Cappa $^{\mathrm{a}-\mathrm{b}}$, J. Rutqvist ${ }^{\mathrm{b}}$, C-F. Tsang ${ }^{\mathrm{b}}$ and A. Thoraval ${ }^{\mathrm{c}}$ \\ ${ }^{a}$ Geosciences Azur, CNRS-UNSA-IRD-UPMC, Sophia-Antipolis - France \\ ${ }^{\mathrm{b}}$ Lawrence Berkeley National Laboratory, Earth Sciences Division, Berkeley - USA \\ ${ }^{\mathrm{c}}$ INERIS, Ecole des Mines de Nancy, Nancy - France
}

* Corresponding author. Fax: (+33) 4.92.94.26.10

E-mail address: guglielmi @geoazur.unice.fr (Y. Guglielmi)

\begin{abstract}
To better understand the role of groundwater-level changes on rock-slope deformation and damage, a carbonate rock slope $(30 \mathrm{~m} \times 30 \mathrm{~m} \times 15 \mathrm{~m})$ was extensively instrumented for mesoscale hydraulic and mechanical measurements during water-level changes. The slope is naturally drained by a spring that can be artificially closed or opened by a water gate. In this study, a 2-hour slope-dewatering experiment was analyzed. Changes in fluid pressure and deformation were simultaneously monitored, both at discontinuities and in the intact rock, using short-base extensometers and pressure gauges as well as tiltmeters fixed at the slope surface. Field data were analyzed with different coupled hydromechanical (HM) codes (ROCMAS, FLAC ${ }^{3 \mathrm{D}}$, and UDEC).

Field data indicate that in the faults, a $40 \mathrm{kPa}$ pressure fall occurs in 2 minutes and induces a 0.5 to $31 \times 10^{-6} \mathrm{~m}$ normal closure. Pressure fall is slower in the bedding-planes, lasting 120 minutes with no normal deformation. No pressure change or deformation is observed in the intact rock. The slope surface displays a complex tilt towards the interior of the slope, with magnitudes ranging from 0.6 to $15 \times 10^{-6} \mathrm{rad}$.

Close agreement with model for both slope surface and internal measurements is obtained when a high variability in slope-element properties is introduced into the models, with normal stiffnesses of $\mathrm{k}_{\mathrm{n} \_ \text {faults }}=10^{-3} \times \mathrm{k}_{\mathrm{n} \_ \text {bedding-planes }}$ and permeabilities of $\mathrm{k}_{\mathrm{h}_{-} \text {faults }}=10^{3} \times \mathrm{k}_{\mathrm{h} \_ \text {bedding-planes. }}$. A nonlinear correlation between hydraulic and mechanical discontinuity properties is proposed and related to discontinuity damage. A parametric study shows that $90 \%$ of slope deformation depends on HM effects in a few highly permeable and highly deformable discontinuities located in the basal, saturated part of the slope while the remaining $10 \%$ are related to elasto-plastic deformations in the low-permeability discontinuities induced by complex stress/strain transfers from the high-permeability zones. The periodicity and magnitude of free water-surface movements cause 10 to $20 \%$ variations in those local stress/strain accumulations related to the contrasting HM behavior for high and low-permeable elements of the slope. Finally, surface-tilt monitoring coupled with internal localized pressure/deformation measurements appears to be a promising method for characterizing the HM properties and behavior of a slope, and for detecting its progressive destabilization.
\end{abstract}

Key words: Fracture; Rock slope; Mesoscale; In situ poroelastic measurements; Hydromechanics; Numerical modeling; Tiltmeter monitoring; Damage.

\section{Introduction}

Understanding coupled groundwater and mechanical processes in complex fracturedporous rocks is essential for the safety and efficiency of subsurface and slope-stability engineering, and thus for the security and economic well-being of the general public. Although poorly documented, water is often mentioned as a triggering mechanism for failure of rocks with well-developed pre-existing fractures networks, and thus the cause for rock 
slides [1]. Sartori et al. [2] observed that "explosion-like failure of rock slabs and sprays of water under pressure" characterized the events preceding the 1991 Randa rockslide $\left(22 \times 10^{6}\right.$ $\mathrm{m}^{3}$ ) in Switzerland. Similar observations have been made in other cases in which events have been triggered close to and above the main spring draining the aquifer contained in a slope. Groundwater can also play a role in accelerating rock-slope movements. For example, Cappa et al. [3] found clear correlations between periods of seasonal water infiltration and accelerations of the La Clapière rock slide $\left(60 \times 10^{6} \mathrm{~m}^{3}\right)$ in the Southern French Alps. Such observations indicate that groundwater flow and mechanical deformations are intimately coupled and cannot in general be analyzed independently of each other.

These coupled effects are especially prevalent in fractured rock, where the groundwater flow concentrates along pre-existing discontinuities or along discontinuities induced by progressive failure occurring in the massif. Such coupled effects have been studied primarily through laboratory specimens on single fractures, and secondarily in the field, within the deep saturated zone of large fractured rock masses [4-7]. Usually, intact rock has relatively low permeability. Numerous laboratory tests on single fractures show that fracture permeability is quite sensitive to changes in fracture aperture, which in turn depend on the state of stress acting on the fracture [8-11]. Under normal stress loading, fracture permeability depends on effective stress variation, as a function of the amount and spatial distribution of void spaces between the fracture surfaces [12]. A decrease in fracture voids under increasing stress leads to a decrease in fracture permeability. Under shear stress, induced fracture-slip permeability first increases because of dilatancy. Then, gouge production linked to fracture asperity damage may induce a clogging of the void spaces and a lowering of fracture permeability [13, 14].

In fractured rock masses, within a complex fracture-network geometry, hydromechanical processes depend on the coupled effects within fractures and their hydraulic and mechanical connections with other fractures, as well as the orientation and magnitude of the effective stress state $[15,16]$. In addition, scale effects and sampling disturbances indicate that hydraulic and mechanical properties derived from a small-scale laboratory sample might be significantly different from that in the field $[7,17,18]$. Hydraulic well testing applied to investigate in situ coupled hydromechanical effects in fractured rock [17-21] showed that the in situ behavior of a single fracture strongly depends on the hydromechanical behavior of the surrounding fractured rock mass. Experiments that carried out simultaneous measurements at different locations within an in situ fracture network $[9,22]$ showed that the time-dependent response of the fracture network is being characterized by a delayed response, with a time lag of a few minutes to a few hours at some points [22], and reversed pressure-deformation variations that were linked to stress transfers effects from one point to another. For example, pressure increased in some fractures located at a distance from an experimental well, where an induced pressure drawdown caused an effective stress variation affecting a larger volume of the reservoir [23].

The coupled hydromechanical behavior of fractured rock has been extensively studied in rock mechanics over the past 30 years, in research programs concerned with flow in fractures at great depths, under high stresses, and with a relatively small hydraulic aperture and high stiffness [24]. Coupled processes in rock slopes or at shallow depths are seldom studied because those effects are difficult to quantify, are often three-dimensional, and involve highly permeable fractured media under a very low stress state, which can be modified at different time scales with the development of slope destabilization [25-27]. 
The stability of a rock slope depends on the rockmass mechanical strength and on the state of stress inside and at the boundaries of the slope [28]. Slope strength depends on the fracturenetwork geometry, individual fracture strength, and intact rock strength. The state of stress in a slope is complex, with zones of low stress close to the middle and upper part of the slope, and zones of high stress at the toe and deep within the slope [29, 30]. It is commonly acknowledged that tensile stresses develop from the middle to the top of the slope and may induce traction opening of existing fractures. Deeper within the slope and at the slope toe, all principal stresses are compressive and may induce sliding on fractures (depending on their orientation). Assuming this initial highly heterogeneous state of stresses inside a highly discontinuous rock mass, failure may develop in a variety of modes, through a single fracture plane (plane failure) to a combination of several discontinuities connected together (step path and step wedge failure). Moreover, failure occurs both along pre-existing discontinuities and within rock bridges made of intact rock between the discontinuities.

Groundwater seasonal flow is one major trigger that governs the stability of rock slopes [31, 32]. The hydrogeology of a rock slope depends on land surface topography, hydrogeological properties, and the infiltration of rainfall and melting snow. Furthermore, winter ice can prevent outflows and increase water pressures in the slope [33]. An unconfined aquifer is drained through seepage points located at the foot of the slope. Depending on the hydrologic conditions, the free water-surface elevation changes with time; being relatively high during heavy precipitation periods and relatively low during dry periods. In the basal, saturated zone of the slope, interstitial pressures $\left(\mathrm{P}_{\mathrm{f}}\right)$ act to reduce effective normal stress in discontinuities [34-36]. Compressive effective normal stresses $\left(\sigma_{n}{ }^{\prime}-P_{f}\right)$ press the opposing discontinuity walls together and resist sliding motion along the discontinuity surface, which can be induced by shear stresses $(\tau)$ acting parallel to the discontinuity plane. A reduction in the effective normal stress state leads to the normal opening of discontinuities, inducing a reduction of the internal shear strength of discontinuities or of the failure surface [37]. Deep in the slope and at the slope toe, where principal stresses are all compressive, an interstitial pressure increase can then induce slip on favourably oriented discontinuities. In zones close to the surface and in the upper part of the slope where tensile stresses develop, a traction induced opening of discontinuities can occur. In both locations, coupling between groundwater pressure and deformation is a major factor in slope elastic and inelastic deformation. When slope discontinuities are deformed, their hydraulic properties and their network connectivity are modified. Dilatancy and crushing from asperities can occur, and thus the hydrogeology of the slope can change. Additionally, underground hydrochemical and erosional effects occur in the slope [38-40]. Water can dissolve or transform minerals in the fillings of some discontinuities, and thus reduce the material strength of the slope. Highly conductive flowpaths can be generated, and increased particle erosion can take place [41]. These disturbancies induce progressive damage of the slope that can evolve into catastrophic failure when slope strength is sufficiently lowered.

As a result of the importance of such hydromechanical (HM) effects, we developed over many years a field experiment dedicated to the study of these effects in fractured reservoirs, at an intermediate scale between laboratory and massif scales. The Coaraze Laboratory located in southern France [42] is a mesoscale fractured carbonate reservoir $(30 \mathrm{~m} \times 30 \mathrm{~m} \times 15 \mathrm{~m})$ with an unconfined aquifer drained by a natural spring. For our purposes, the spring was artificially closed to allow measurements, with a water gate enabling control of the reservoir piezometric level (by opening or closing the gate). Moreover, reservoir fractures were extensively instrumented for fully coupled hydraulic and mechanical measurements during piezometric level changes. It was shown that the in situ hydromechanical behaviour of a 
single fracture significantly depended on fracture intrinsic hydraulic and mechanical properties (hydraulic aperture and normal stiffness), on the stiffness of the surrounding intact rock, and on the properties and geometry of the surrounding fracture network [20]. Therefore, we developed a protocol of pulse-tests injections in fractures within boreholes with synchronous pressure-deformation measurements that proved to be efficient at estimating both the in situ hydraulic permeability and mechanical stiffness of fractures. Compared to standard purely hydraulic approaches, this protocol showed that ignoring coupled hydromechanical effects could lead to a $25 \%$ error in estimating fracture hydraulic properties. Order-of-magnitude contrasts 10 to 1000 in both hydraulic and mechanical properties were determined among the reservoir fractures, and it was shown that these contrasts controlled the mesoscale hydromechanical behavior of the reservoir [22].

In this paper, the main process of interest is the Coaraze slope deformation associated with hydromechanical effects induced by free water-surface movements in the basal fractured aquifer (artificially controlled by opening/closing the water gate). Such effects which involve complex interactions among several families of large pre-existing discontinuities have never really been explored at the mesoscale. Our primary interest is to estimate whether the high local variability in fracture hydraulic and mechanical properties (estimated from previous Coaraze studies) can be related to progressive mechanical damage of the slope. Our secondary interest is to better understand how this local heterogeneity of properties could be related to slope stability in response to free water-surface movement. In the field experiments studied in this paper, free water-surface movements of up to $8 \mathrm{~m}$ were controlled by closing and reopening the water gate. Changes in fluid pressure and deformation were simultaneously monitored within the various discontinuities and the intact rock, using short-base extensometers, pressuremeters, and tiltmeters fixed at the slope surface. Field data were analyzed using different modeling techniques, based on finite-element, finite-difference and distinct-element models of the rock slope. The influence of several key parameters on the hydromechanical behavior of the fractured rock slope was then evaluated through a sensitivity study, pointing toward an optimal method to characterize a rock slope and its hydromechanical response to water level changes.

\section{Coaraze Site and our Rock Slope Stability Test Setup.}

The site of the Coaraze Laboratory has been well characterized geologically, geometrically, hydrogeologically, and mechanically, during numerous previous studies carried out at the site (For more details, see [20,22,42-44]). The site corresponds to the lower $15 \mathrm{~m}$ section of a $40^{\circ}$ $60^{\circ}$ dipping slope comprised of a thick sequence of fractured limestone (Figures 1a and b). The slope is cut by 12 parallel bedding-planes, with a $040^{\circ}$ trend dipping $45^{\circ} \mathrm{SE}$, and two sets of approximately orthogonal near-vertical faults, with $050^{\circ} / 070^{\circ}$ trends dipping $70^{\circ}$ to $90^{\circ}$ NW and $120^{\circ} / 140^{\circ}$ trends dipping $75^{\circ}$ to $90^{\circ} \mathrm{NE}$. There are 12 well-identified faults with a decametric continuity in the slope that form a fracture network with 0.5 to $2 \mathrm{~m}$ spacing (Figure 1c). Discontinuities with a metric to below metric continuity correspond to minor bedding-planes and fractures, located within $20-50 \mathrm{~cm}$ thick bands centered on the nearvertical faults (Figure 1b). The mechanical properties of the rock matrix, previously determined from laboratory testing, indicated Young's modulus values ranging from 44.4 to $70 \mathrm{GPa}$ and Poisson ratios of 0.29 to 0.34 . Hydraulic and mechanical fracture properties were determined in situ from 10 pulse tests. In each test, a single fracture was isolated with inflatable packers set in a borehole perpendicular to the fracture plane. Pressure and normal deformation curves-versus-time were used to back-calculate the following average hydraulic permeabilities, $\mathrm{k}_{\mathrm{h}}[20]$ : $\mathrm{k}_{\mathrm{h}_{\_} \text {faults }}=10^{2} \times \mathrm{k}_{\mathrm{h} \_ \text {bedding-planes }}=10^{7} \times \mathrm{k}_{\mathrm{h} \_ \text {matrix }}=10^{-4} \mathrm{~m} / \mathrm{s}$. The following 
normal stiffnesses, $\mathrm{k}_{\mathrm{n}}$ were also calculated: $\mathrm{k}_{\mathrm{n} \_ \text {faults }}=0.4 \times \mathrm{k}_{\mathrm{n} \_ \text {bedding-planes }}=40 \mathrm{GPa} / \mathrm{m}$. At the single fracture scale, a 50\% variation in permeability and stiffness values was observed.

The slope topography is roughly oriented N-S and bounded to the west by a small $040^{\circ}$ trending valley and to the south by a $0140^{\circ}$ trending fault scarp. The slope contains a minor aquifer naturally drained by a spring (average annual yield of $0.012 \mathrm{~m}^{3} / \mathrm{s}$ ) that discharges downstream of the valley at a vertical impervious fault contact between permeable limestone and impermeable glauconious marls. This fault serves as a natural dam for water stored upstream in the slope. The spring is artificially controlled with a water gate. When the gate is completely closed, fluid pressures stabilize at about $8 \mathrm{~m}$ above the gate (Figure $1 \mathrm{~b}$ ).

Inside the slope's basal aquifer, changes in fluid pressure and deformation were simultaneously monitored at single discontinuities and in the rock matrix, using short-base extensometers and pressure gauges. At several so-called coupled pressure-strain points, two sensors were installed (by two small borings, Figure 1d) so as not to disturb the state of stress inside the reservoir. Pressure measurements were carried out using a vibrating-wire interstitial pressure sensor with an accuracy of $0.5 \mathrm{kPa}$. Strain measurements were conducted using a $0.15 \mathrm{~m}$ long RockTest-Telemac vibrating-wire extensometer, with an accuracy of $0.5 \mu \mathrm{m} / \mathrm{m}$. In this paper, we focus on four coupled pressure-strain points all set in the cross section $A B$ perpendicular to the slope at different depths and on different slope elements (Figure 1b):

- two faults were instrumented : Fault F0 (point E11 in Figure 1b) and Fault F2 (points HM1, HM2). Point E11, located at the shallow depth of $1 \mathrm{~m}$, monitors the shallow hydromechanical response of the faults at the slope toe. Points HM1 and HM2 monitor Fault F2 hydromechanical response at a depth of $5 \mathrm{~m}$ in the slope.

- 1 bedding-plane located at the slope toe was instrumented at a depth of $1.8 \mathrm{~m}$ (Point E8/P2); The intact rock deformation and pressure was also monitored at the slope toe at points E12 and $\mathrm{P} 1$ at depths of 1.5 and $3 \mathrm{~m}$, respectively.

Within the frame of this study, four short-base bi-directional tiltmeters, three Applied Geomechanics sensors (755 series, having an accuracy of $1 \mu \mathrm{rad}$ ) and one Blum tiltmeter with a $0.1 \mu \mathrm{rad}$ accuracy were placed on the cross section AB (B3, B2, Blum, and B1 in Figures $1 \mathrm{a}, \mathrm{b}$ and e). Surface and internal measurements were synchronously registered with a 2minute sampling-rate interval, using Gantner IDL101 and Campbell CR10X data stations. These stations were located very close to the sensors (a few meters) and wrapped with thermo-isolating materials, so that temperature effects on connecting cables were negligible. Experiments were performed at night between 11 p.m. and 5 a.m., when air temperature variations were less than $0.1^{\circ} \mathrm{C}$, to assure that temperature variations had minimal effect on the tilt measurements.

\section{Coaraze Slope HM Response: Experimental Results}

Initial conditions corresponded to a closed water gate, so that the entire basal section of the slope was fully saturated. The water gate was then opened for a two-hour period to induce a free water-surface drawdown of $80 \mathrm{kPa}$. Then, the water gate was closed again, and free water-surface buildup followed a few hours afterwards.

When the water gate was opened, contrasting hydromechanical behavior was observed, not only among faults, bedding-planes, and intact rock, but also within the same fracture plane. In vertical faults, the pressure fell to zero in less than 120 seconds, and an associated normal closure of faults (Figure 2, points HM1, HM2 and E11, and negative deformation variation- 
versus-time on graphs) was measured. Depending on the points, the deformation magnitudes were -0.5 to $-6 \mu \mathrm{m} / \mathrm{m}$. Such differences in magnitudes were also observed at points located on the same fault and at the same depth $(5 \mathrm{~m})$, as for example with Fault F2 (Figure 1a), where points HM1 and HM2 (1 m distant from each other) showed deformation magnitudes of -2 and $-0.5 \mu \mathrm{m} / \mathrm{m}$, respectively. In bedding-planes, the pressure drawdown was a factor of 17 slower than in vertical faults (points E8/P2 in Figures 1a and 2), and it took 2,000 to 5,000 seconds to fall to zero at these points. Moreover, no normal deformation was measured at Point E8. In the intact rock, no pressure variation (P1 on Figure 2) and no deformation (E12) were measured.

The raw tilt observations at the slope surface were filtered from temperature and earth-tide effects. In Figure 2, only tilt in the direction of the cross section $A B$ plane is presented. Pressure drawdown effects were clearly seen on all tiltmeters except for B1, where a complex oscillating signal was recorded (Figure 2). Tilt magnitudes of -0.5 to $-8 \mu \mathrm{rad}$ were measured. Time variations of tilt, which are quite complex, can be schematically described by a fast initial variation within the first 120 -second period, followed by a slow variation from 2,000 to more than 6,000 seconds long. The rapid initial tilt was correlated to closure of faults that occurred within the same time delay when there was a pressure drawdown in the faults (e.g., at points HM1 and HM2). The subsequent slow variation was not clearly correlated to any internal measurements.

\section{Interpretation}

\subsection{Modeling objectives and protocol}

The objectives of the modeling were: (1) to analyze pressure-deformation and tilt measurements performed on the Coaraze slope, and (2) to perform a parametric study of hydromechanical processes that can affect a fractured slope deformation, using the Coaraze slope geometry as a reference.

Two numerical modeling approaches were applied to simulate HM processes in the fractured rock slope. The first approach, the finite element and finite difference methods, used the ROCMAS [45] and FLAC ${ }^{3 \mathrm{D}}$ [46] codes. These codes were applied to investigate leakage among rock matrix, bedding-planes, and faults, as well as to investigate the associated poroelastic effects of a free water-surface in the slope. Two independent codes were used to improve confidence and quality in models results. Using this continuum approach, discontinuities cutting the entire slope (and instrumented) were represented by $0.05 \mathrm{~m}$ thick solid elements, while the other fractured zones of the slope were represented as equivalent anisotropic, continuous zones in which the degree of mechanical and hydraulic anisotropy was varied. Both codes were developed from Biot's theory of consolidation [34] and were used in the fully coupled calculation mode. Changes in variation of fluid content are related to changes in pore pressure, saturation, and mechanical volumetric strain. Two fluid-mechanical interactions were described: (1) changes in pore pressure cause changes in effective stress, which affect the response of the solid; and (2) fluid in a zone reacts to mechanical volume changes by changing its pore pressure. Fluid transport is governed by Darcy's law. This approach allows a relatively high contrast in hydraulic and mechanical properties between zones and a realistic representation of the slope saturation state.

The second approach used the distinct element code UDEC [46, 47] to describe hydromechanical effects in the discontinuities that cut through the entire slope, mainly the 
effects linked to the induced tangential displacements. In this discontinuum approach, conductive discontinuities are viewed as interfaces between impervious, deformable blocks. Fluid flow is calculated using the cubic law, based on the parallel plate model [48]. The hydraulic aperture of the fracture is dependent on the mechanical displacement of the fracture and on block deformation; conversely, fluid pressures in the fracture affect mechanical behavior. This approach enables both tangential and normal displacements along discontinuities better described than in the continuum approach.

In the numerical analyses conducted herein, discontinuities and the rock matrix were considered to be linearly elastic. A 2D model was developed that represented Cross Section $\mathrm{AB}$ (Figure 3), perpendicular to the local slope direction (Figure 1b). Land-surface topography was carefully represented, and several model geometries were tested to determine the points at which boundary effects were negligible. A $25 \mathrm{~m} \times 21 \mathrm{~m}$ model was chosen, about a factor of 1.5 larger than the instrumented slope. The stress concentration at the valley base was calculated from large scale models in which both valley sides were simulated. To reproduce this symmetrical valley effect, we applied a constant stress of $6.5 \times 10^{5} \mathrm{~Pa}$ on the bottom two meters of the topographical left boundary. The remainder of the topographical surface was free to move.

Fixed $\mathrm{X}$ and fixed $\mathrm{Z}$ displacement conditions were imposed on the right and basal boundaries respectively. The fracture network was represented in two different ways. In the continuum analyses, the four subvertical faults F0, F1, F2, and F3, and the three low-dipping bedding-planes located in the basal part of the slope, were discretized (Figure 3a). In the discontinuum analysis with UDEC, all the bedding-planes and faults were discretized (Figure 3b). All model hydraulic boundaries were impervious. A $8 \mathrm{~m}$ thick fully saturated zone was assumed at the basal part of the model, except in the left basal corner, which was set as impervious to represent the impervious glauconite layer. This imposed piezometric level introduced an overestimation of initial piezometry compared to field experiments of 0 to $3 \mathrm{~m}$ in faults and of 2 to $5 \mathrm{~m}$ in bedding-planes and in intact rock matrix.

In the continuum models, discontinuities that extended over the entire slope were divided into segments of various lengths. These segments were defined as groups in which hydraulic and mechanical parameters could be varied (from one segment to the other) within the interval of values deduced from in situ tests. Zones between discontinuities were also identified as groups to be affected with equivalent properties. This setup enabled us to consider discontinuities of a metric continuity in matrix zones located between the discretized bedding-planes and the faults at the basal part of the slope, and all the discontinuities in the middle and upper parts of the slope. Equivalent properties were estimated using equations (1) and (2) [7]:

$$
\frac{1}{E_{e q}}=\frac{1}{E_{\text {matrix }}}+\frac{1}{n \times k_{n}}
$$

where $E_{e q}$ is the compliant Young's modulus, $E_{\text {matrix }}$ is the intact rock modulus that was measured in the laboratory (Table 1), $n$ is the fracture spacing per meter of faults or beddingplanes and $k_{n}$ is the normal stiffness of faults and bedding-planes :

$$
k_{h e q}=\frac{a^{3}}{6 \times n}
$$


where $k_{h e q}$ is the equivalent hydraulic permeability and $a$ is the fracture hydraulic aperture.

In the discontinuum model, similar properties were attributed to all discontinuities that extended through the entire slope, and only the contrasting properties between bedding-planes and faults were varied. Blocks between the discontinuities were assigned intact rock matrix properties.

In each simulation with FLAC ${ }^{3 \mathrm{D}}$, ROCMAS, and UDEC, the model was first run to reach a steady state having a filled slope aquifer with the water table at $8 \mathrm{~m}$. After the steady-state initial conditions were set, emptying of the slope aquifer was simulated by decreasing the fluid pressure to zero at the foot of the four faults (F0, F1, F2, and F3). Then, after 2 hours, the fluid pressure was set again at the foot of each fault. How model size and boundary conditions affected the HM numerical responses of discontinuities in the slope were investigated. Larger models representing both sides of the valley introduce less than a $10 \%$ variation in the results, which remains within the accuracy of measurement.

\subsection{Measurements Interpretation}

The three numerical approaches roughly showed the same results with a 5 to $10 \%$ difference between the two continuum models and a 5 to $25 \%$ difference between the continuum and discontinuum models, depending on the points considered (Figure 4). In Figure 4, results are grouped in the thick grey curve when differences between models remain within the $[0,10 \%]$ interval. All models captured observed pressure and deformation variations in faults.

The discontinuum approach using the UDEC code showed different results for pressure at bedding-plane P2, but no significant differences at deformations. In the UDEC results, pressure variation at $\mathrm{P} 2$ was very high in the first minutes, but after that fell to almost zero until the end of the simulated drawdown period. The calculated curve shape was far from those calculated with the continuum approach, although pressure variation was of the same order of magnitude. Such a difference is attributed to differences in the flow calculation laws between UDEC and the continuum codes. Using UDEC, the cubic law depends exclusively on the fracture hydraulic aperture; no fracture storativity is considered. In continuum approaches, both permeability and storage of elements are considered, such that when pressure variations are controlled mainly by hydraulic aperture (which is the case for highly permeable vertical faults), all models display the same result. Within the low-permeable bedding-planes, pressure variations are controlled by both permeability and storage terms in the diffusivity equation, and cannot be captured by UDEC simulations.

In all the models, surface tilts were approximately restored. The best-fit curve was obtained for B2 and B3 points located close to the saturated part of the slope. Tilt variations at Blum and $\mathrm{B} 1$ points, located higher in the unsaturated part of the slope, were not well reproduced. Blum tilt was underestimated by a factor of 2, and B1 tilt oscillations were not reproduced. In the discontinuum approach, calculated tilts show no variations after the first minutes of the imposed drawdown compared to continuum results, where a slow tilt rate is observed until 7200 seconds. This slow tilt rate is related to the slow emptying of bedding-planes that is well restituted in continuum calculations.

When pressure is instantaneously set to zero at the foot of the faults, a quick pressure fall to zero occurred in faults F0, F2, and F3 (Figure 5a). Pressure fall is slower in F1 because it is 
$1 / 10^{\text {th }}$ as permeable as the other faults. Until 2,000 seconds elapsed, there was no significant pressure variation in the rock matrix; pressure only began to fall in the bedding-plane segments connected to faults. After 2,000 seconds, all fault zones were completely emptied and unsaturated (Figure 5b). At 7,200 seconds, pressure fall propagated in bedding-planes and in the matrix adjacent to discontinuities (Figure 5b). In contrast to faults, all the lowpermeable zones remained saturated with water, having only undergone a pressure drawdown.

Slope-displacement magnitudes decreased towards the interior of the slope and from the basal, saturated part towards the upper, unsaturated part (Figure $5 \mathrm{c}$ and $\mathrm{d}$ ). The heterogeneous displacement field was characterized by a superficial zone located between the land surface and Fault F1, where displacement vectors rotated from 0 to $40^{\circ}$ to the interior of the slope. Magnitudes in this region are 0.25 to $2.4 \times 10^{-5} \mathrm{~m}$. In a deep zone located below fault $\mathrm{F} 1$, displacement vectors rotated to dip angles of $10^{\circ}$, almost perpendicular to faults, and displacement magnitudes lowered to values of 0.05 to $0.5 \times 10^{-5} \mathrm{~m}$.

Within the initial 2,000 seconds, slope deformation was controlled by fault closure under fluid-pressure drawdown. Fault closure was generally normal, with relatively high magnitudes in the saturated portion of the fault compared to the unsaturated portion. For example, in Fault F2, normal closure at Point HM1 in the saturated portion is $-1.5 \times 10^{-6} \mathrm{~m} \cdot \mathrm{m}^{-1}$ and $-0.15 \times 10^{-6}$ $\mathrm{m} . \mathrm{m}^{-1}$ at Point HM3 in the unsaturated portion (Figure 5c). Normal closure of the fault was accompanied by a $0.1 \times 10^{-6} \mathrm{~m} . \mathrm{m}^{-1}$ tangential extension in the lower saturated HM1 part of the fault and by a $-0.15 \times 10^{-6} \mathrm{~m} \cdot \mathrm{m}^{-1}$ tangential compression in the upper HM3 part. Deformation magnitude depends on fault stiffness and on the state-of-stress in the fault. Indeed, high magnitudes of $12 \times 10^{-6} \mathrm{~m}$ calculated at Point HF1 on Fault F1 (Figure 5c) were related to a factor-of-10 lower fault normal stiffness compared to other faults (Table 1). Fault F0, a factor of 10 stiffer than faults F2 and F3, showed a greater deformation (Figure 5c) - of $3 \times 10^{-6} \mathrm{~m}$ at Point HF0, $2 \times 10^{-6} \mathrm{~m}$ at Point HM1, and $1.5 \times 10^{-6} \mathrm{~m}$ at Point HF3 $\mathrm{m}$-because of the very low state of stress on that fault. Fault normal closure induced shear and normal extension on segments of bedding-planes close to faults, with magnitudes of 0.15 to $0.05 \times$ $10^{-6} \mathrm{~m}$ at points E8 and E9 (Figure 5c). Deformation magnitudes within intact rock blocks (Figure $5 \mathrm{c}$ ) of 0.15 to $0.05 \times 10^{-6} \mathrm{~m}$ were within the accuracy of the numerical models.

After 2,000 seconds, fault zones were completely unsaturated, and consequently, no coupled hydromechanical effects occur in the faults. Slope deformation was controlled by normal and tangential closure in bedding-planes, which were drained because of their connection to faults. A 0.2 to $0.6 \times 10^{-6} \mathrm{~m}$ normal closure was observed respectively at Points E9 and E8 (Figure 5d). Bedding-plane closure induced a small intact rock extension perpendicular to bedding-planes and a compression parallel to bedding-planes with magnitudes of the same order $\left(0.05\right.$ to $\left.0.1 \times 10^{-6} \mathrm{~m}\right)$, which was within the accuracy of the numerical models. Bedding-plane closure also induced a tangential compression of 0.1 to $0.15 \times 10^{-6} \mathrm{~m}$ on faults at points HM1, HF1 and HF3 (Figure 5d).

Slope surface tilt variation mostly occured between 0 and 2,000 seconds, when the vertical fault normal closure was linked to pressure drawdown in faults (Figure 5c). Tilt magnitudes and rates were much higher close to the basal, saturated part of the slope than in the upper, unsaturated part. Indeed, tilt is toward the valley and varies from 4 to $0.2 \times 10^{-6}$ radians from the toe to the middle of the slope. In that zone, the block bounded by the land surface and by Fault F1 indicated a much larger tilt than the remainder of the slope. Tilt variation at the slope top remains within the accuracy of the models, meaning that tilt variations measured at B1 certainly are not related to pressure variations in the aquifer, or that a local complexity needs to be introduced in the model close to B1. After 2,000 seconds, a tilt variation is observed at 
the two points located in the middle of the slope, related to bedding-plane deformation (Figure $5 \mathrm{~d})$.

\section{Influence of Discontinuity HM Properties and Responses on Slope Movements (FLAC $^{3 \mathrm{D}}$ Sensitivity Study)}

\subsection{Influence of fractures with a decametric continuity}

The effect of the fracture-network geometry on slope HM behavior was tested by comparing the following numerical cases (Figure 6):

- Model I: A completely homogeneous slope with equivalent hydraulic and mechanical properties.

- Model II: A homogeneous slope with one vertical fault segment corresponding to the basal part of Fault F1. The fault segment has F1 HM properties, and the continuous part of the slope has equivalent properties.

- Model III: A homogeneous slope with vertical faults having constant material properties corresponding to Fault F2 properties at HM1 point. Between the faults, continuous zones are affected by properties equivalent to a discontinuous medium with bedding-planes.

Model I did not reproduce the entire HM behavior of the slope. Pressure drawdown magnitudes and trends were severely underestimated at all points (Figure 6). The higher variations were localized at Points $\mathrm{P} 1$ and $\mathrm{P} 2$, which are closer to the unloading basal boundary than HM1 and HM2. Consequently, a deformation was produced only at points E8, E11, and E12, associated with pressure variation in the basal part of the model. A very small tilt variation of 0.7 to $0.2 \times 10^{-6}$ radians was observed from B3 up to Blum Points. Adding a single vertical fault with a metric continuity to the foot of the model (Model II) increased drainage of the slope close to this segment. Pressure and deformations were still not reproduced. Extension was generated around the segment at Points E8 and E12. Adding the three vertical faults with a decametric continuity (Model III) restitutes pressure and deformation variations in faults with a 5\% discrepancy. Since bedding-planes are not figured, pressure at Point P2 is not restituted and no variation is observed. There is compression at Point E8, but the rate and the $0.2 \times 10^{-6}$ meter magnitude of the deformation display a major 50 to $70 \%$ discrepancy. Since there is no pressure variation at Point E8/P2, this deformation is related to poroelastic closure of the faults. Tilt variation at Point B2 is increased by a factor of 1.8. The deformation of the blocks bounded by the faults is more isotropic when there are no bedding-planes incorporated into the model. The result is that poroelastic closure of faults being not accommodated through sliding along bedding-planes induces a higher global rotation at the slope surface. This rotation is mainly seen in the middle of the slope, the foot being "blocked" by the stress imposed from the other side of the valley and the top being too far from the zone in which the pressure change takes place.

\subsection{Material Properties}

\subsubsection{Hydraulic properties of slope elements (Figure 7).}

The lowering of fault permeability by a factor of 10 to 100 induces a lowering of pressure and deformation rates by a factor of 10 to 100 in faults (Figure 7, HM1). At the end of the 2hours experiment, for $\mathrm{k}_{\mathrm{h} \_ \text {fault }} / 100$, faults were not completely emptied, inducing a factor of 0.3 lower magnitude in fault normal closure. Such slow fault drainage also affects bedding-plane drainage, such that it is somewhat delayed (Figure 7, P2). With the massif less emptied of water, slope tilts displayed slower rates by a factor of 10 to 100 and lower magnitudes by a 
factor 0.5 to 0.8 (Figure 7, Blum, B2, and B3). This finding shows that the rate of the surface tilt curve is strongly related to the rate of the pressure variations in faults. An increase by a factor of 10 in bedding-plane permeability induced a local increase of $50 \%$ in bedding-plane pressure rate and magnitude, and a complete emptying of bedding-planes (Figure 7, P2). It had no influence on the local Bedding plane (E8) and Fault (HM1) mechanical behaviours but it induced a decrease of $55 \%$ in B2 tilt. This finding shows that when bedding-planes are completely emptied of water, a higher effective normal stress applied on the planes increases the planes' shear strength and reduces tangential deformation. Then, the blocks bounded by the faults are stiffer, and the effect of fault poroelastic closing on surface tilt is attenuated. A decrease by a factor of 10 in bedding-plane permeability reduces pressure variation at P2 almost to zero but has no effect elsewhere in the slope. A matrix permeability increase by a factor of 100 induced a $20 \mathrm{kPa}$ pressure variation in the matrix at Point $\mathrm{P} 1$ and a $20 \mathrm{kPa}$ pressure variation in bedding-planes at Point P2. It had no impact on the local deformation of matrix, bedding-planes and faults. It induced a 52\% decrease of tilt at Point B2. This effect is similar to the one induced by a bedding-plane permeability increase. Indeed, a partial emptying of both bedding-planes and matrix induces an increase in the maximum compressive effective stress of blocks bounded by faults that are consequently stiffer, resulting in a global tilt attenuation.

\subsubsection{Mechanical properties of slope elements (Figure 8).}

In our simulations, a change in the mechanical properties of elements had no effect on their hydraulic properties (all pressure curves are the same in Figure 8). A change in fault stiffness by a factor of 10 induces a factor-of-7 change in fault deformation (Figure 8, HM1). A decrease of fault stiffness by a factor of 10 modified the local behavior of the matrix (Figure 8, E12) from a compressive to an extensive deformation. Changes in fault stiffness induced a general change in slope stiffness; a factor-of-10 modification in fault stiffness induced a factor-of-10-to-15 modification in tilt magnitudes (Figure 8, Blum, B2, and B3). Modifications in bedding-plane stiffness mainly affect the local behavior of bedding-planes (Figure 8, E8); a factor-of-10-and-100 lowering of bedding-plane stiffness respectively induced a factor-of-3-and-30 increase in bedding-plane deformation. When bedding-plane stiffness lowering exceeded a factor-of-10, tilt signals were modified by a factor of 0.1 to 0.2 (Figure 8, Blum, B2, and B3). Reducing the matrix by a factor-of-5 was tested and it did not affect the model.

\subsection{Elastic to elasto-plastic constitutive laws (Figure 9).}

Although the Coaraze experiment was performed on a stable slope, the relevance of a purely elastic mechanical analysis of fault and bedding-planes deformations was tested by comparison to an elasto-plastic analysis. Mohr-Coulomb behavior was invoked for slope elements to explore how changing of state could potentially lead to failure along the preexisting discontinuities of the slope, and how a local plastic change could affect the global behavior of the slope. Cohesion (c) and friction angle $(\phi)$ values were taken from the literature, specifically $\mathrm{c}=10 \mathrm{kPa}$ and $\phi=30^{\circ}$ for all discontinuities. Compared to the elastic calculation (Figure 9), the key differences appeared on the bedding-plane (Figure 9, P2-E8), at tiltmeters (Figure 9, Blum, B2 and B3) and, at a lower magnitude, at faults (Figure 9, HM1). A $2.5 \times 10^{-6} \mathrm{~m}$ opening of the bedding-plane (E8) that occured in the first minutes of the experiment was associated with pressure drawdown in vertical faults. Local failure in the bedding-planes induced an increase in bedding-plane permeability by a factor-of-10 that explained the faster and higher pressure drawdown at P2 compared to the elastic calculation. An additional normal closure of faults by a factor-of-1.06 was observed at HM1. Additional 
irreversible tilts were observed at all points with values increased by factors-of-2.5, 2, and 1.2 respectively at points $\mathrm{B} 2$, Blum, and $\mathrm{B} 3$. This analysis shows that the inelastic deformation magnitude is high at bedding-planes, as a result of sliding induced by normal closing of faults. Damage related to this deformation explains the bedding-plane permeability increase. The plastic deformation observed at HM1 shows that inelastic deformation also take place in faults where it is moderate and localized close to the intersections between faults and beddingplanes and close to the slope surface. The additional sliding that takes place mainly on bedding-planes explains the additional inelastic tilt of the slope surface.

\subsection{Effects of free water-surface movements (Figure 9).}

During the two-hour drawdown, the rock mass was not completely drained of water. Indeed, while highly-permeable faults were completely emptied, low-permeable discontinuities and matrix zones remained completely saturated with water, and only a partial pressure drawdown was observed (Figure 5b). Thus, depending on the duration of the unloading period, the slope would likely be more or less emptied of water, and the HM behavior of the slope would be different. Loading/unloading periodic effects were tested by reducing the slope emptying period to 0.5 hours. Then, a few loading/unloading cycles were carried out to simulate free water-surface oscillations. Compared to the 2-hour emptying period (best fit), the pressuredrawdown magnitude was a factor-of-0.9 smaller in the bedding-planes (Figure 9, Point P2), and the pressure buildup was highly asymmetric, since the pressure recovery was not complete before the next imposed pressure drawdown. This is directly linked to the high contrast in permeability between faults and bedding-planes, and also to the fact that faults act as pressure boundaries for bedding-planes. This higher pressure in bedding-planes induced a small difference in the surface tilt at points B2 and Blum, located above the saturated zone of the slope-a $0.3 \times 10^{-6}$ rad additional tilt for B2 and a $0.3 \times 10^{-6}$ rad smaller tilt for Blum. After three loading/unloading cycles with a 0.5 -hour period, an additional deformation of the medium and upper parts of the slope clearly occured (compared to the best fit) (Figure 9, points B2 and Blum). This additional deformation is related to the fact that when pressuredrawdown duration is short, the pressure decrease in bedding-planes is much smaller, while it remains the same in faults. As a result, effective normal stress applied on the bedding-planes is smaller and induces a lowering of bedding-planes shear strength. Thus, bedding-plane hydromechanical response to fault deformation induced by short-duration water emptying is of a higher magnitude compared to long duration water emptying that induces high-pressure decreases and associated shear strength increases on bedding-planes.

\section{Discussion}

This detailed analysis of the Coaraze slope experiment raises some general considerations with respect to the hydromechanical properties and behavior of fractured rock slopes subject to free-water surface oscillations (Figure 10 and Table 2):

\subsection{Slope HM properties: Characterization of discontinuity damage}

The work presented in this paper represents an opportunity to simultaneously correlate a relatively large set of coupled pressure-deformation measurements with fracture properties at different locations in the Coaraze slope. Points estimated from this study (Table 1) were compared to values previously determined during localized hydromechanical pulse tests [20] (Figure 10). Fault normal stiffnesses estimated in this study vary considerably within the same fault and between faults (Figure 10a). Values all remain within a 10\% discrepancy compared 
to previous estimations, of 0.8 to $1.6 \times 10^{9} \mathrm{~Pa} / \mathrm{m}$ (point $\mathrm{F} 1$ compared to previous values at points 1 and 3, Figure 10a), and 22 to $50 \times 10^{9} \mathrm{~Pa} / \mathrm{m}$ (F2-HM1, F2-HM2 and F3 compared to previous values at points 4 and 5, Figure 10a). Bedding-plane normal stiffness is very high, with values ranging from 200 to $600 \times 10^{9} \mathrm{~Pa} / \mathrm{m}$. In the continuum analyses, the best fit value of $600 \times 10^{9} \mathrm{~Pa} / \mathrm{m}$ (Figure $10 \mathrm{a}, \mathrm{BP}\left(\mathrm{FLAC}^{3 \mathrm{D}}\right)$ ) appears much larger than in the discontinuum analyses (Figure 10a, BP(UDEC)), and it does not match previously estimated values (points 8 and 9, Figure 10a). Nevertheless, the sensitivity study conducted in this paper (see Chapter 5.2.2 and Figure 8) showed that lowering this value by a factor less than 10 did not affect slope behaviour, indicating that the $\mathrm{BP}\left(\mathrm{FLAC}^{3 \mathrm{D}}\right)$ value is certainly overestimated.

Variation in hydraulic permeabilities was also very large, with values of $10^{-8}$ to $10^{-10} \mathrm{~m}^{2}$ for faults and values of $10^{-11}$ to $10^{-12} \mathrm{~m}^{2}$ for bedding-planes. All values remained within a $50 \%$ discrepancy compared to previous estimations. Such a discrepancy can be explained by the major difference in the experimental protocols used to estimate the permeabilities. Previous values were estimated from pulse-test experiments that restitute a local estimation of the tested fracture. Values estimated in this paper come from the analysis of a slope-scale pressure experiment and certainly correspond to a fracture-scale average value.

Figure 10a displays a highly nonlinear correlation between the permeability and the normal stiffness of discontinuities (Figure 10a). This correlation is explained both by the large properties contrasts between the faults and bedding-planes, and by the large variability of properties within a given type of fractures. Since there are several parameters that describe the hydraulic permeability of a fracture (hydraulic aperture, roughness, and tortuosity; see [48]), it is hard to give a simple explanation for the high permeability of a fracture. In the very special case of shallow discontinuities in slopes, it is commonly observed that discontinuities that are almost parallel to the slope direction and dip (roughly the case of vertical faults at Coaraze) are in general widely opened [49-50]. We can assume that their tortuosity is quite low and that their roughness is small compared to their aperture. Elsewhere, it has been observed that there are a small number of centimetric contacts between the two walls of those discontinuities [51], as a result of the progressive failure of those contacts due to slope decompression. The small number of contacts could explain the relatively low stiffness of discontinuities, which in turn are likely to display a large hydraulic aperture and a small stiffness. Such a mechanism could explain the property variation from Point 3 to 1 on Fault F1, a factor-of-10 lowering of the normal stiffness and a factor-of-20 increase of the permeability respectively, and between Points 4,5 to 2 on fault F2, a factor-of-2.4 lowering of the normal stiffness and a factor-of100 increase in the permeability (Figure 10a). Points 1 and 2 are located on shallow segments of the faults and are more disturbed than points 3,4 and 5, which are located deeper (Figure 10b). On the other hand, bedding-planes which are slightly affected by decompression effects and subjected to higher compressive stresses, mainly because of their inward dipping orientation, are more closed than faults. In this case, with more contacts between the two walls of the discontinuity (emphasized by the occurrence of marly fillings), bedding-planes would display higher normal stiffnesses and lower permeabilities. Nevertheless, there is a high variability in bedding-planes properties corresponding to bedding-plane damage characterized by permeability increase of two orders of magnitude and a decrease of normal stiffness of a factor-of-3, from points 9 and 8, located at $5 \mathrm{~m}$ and $2 \mathrm{~m}$ depths, respectively, to points 7 and 6 , located at 0.5 and $1 \mathrm{~m}$ depths, respectively (Figures 10a and b).

To our knowledge, such a correlation between hydraulic and mechanical properties of fractures has never been established in situ. First, it enables a reduction in the number of parameter values feeding into the coupled HM model considering the variation of fractured 
rock permeability with induced damage. Second, it clearly appears that slope damage can induce order-of-magnitudes variations in discontinuity properties within the first few meters of a slope: a lowering by a factor-of-2-10 of normal stiffnesses and an increase of a factor of 20 to 100 of permeabilities.

\subsection{Free water-surface movement effects on slope deformation}

Deformations that take place in the slope's basal aquifer affect the entire slope (Figure 10b). In the zone of free water-surface oscillations, the normal closure of discontinuity segments that are emptied of water, and deformation magnitudes decrease from the land surface to the inside of the slope. The stress concentration at the toe of the slope emphasizes the closing of the discontinuities that are emptied of water. Both effects add a global rotational component to slope movements that are accommodated through sliding along low permeable discontinuities that remain saturated with water at a fluid pressure close to initial. When there is an increase in interstitial pressure, there is global slope swelling; when there is a decrease in interstitial pressure, there is global slope sagging.

We can expect that the extension of the slope area involved in the HM induced rotational movement for the most part depends on the periodicity, shape, and magnitude of oscillations. Because of the coupling of pressure and deformation, the pressure magnitude will directly influence the deformation magnitude. Periodicity is a time-dependent parameter related to the hydraulic permeability of slope elements. In the case of a heterogeneous and disturbed fractured slope, a wide range of permeabilities will induce a wide range of pressure signals within slope elements, linked to the periodicity of the oscillations. Short period oscillations, like those induced by daily infiltrations and artificial drainage/injection actions, will exclusively affect pressures in the highly-permeable elements of the slope. Long-period oscillations, like those linked to seasonal climate fluctuations, will affect a wider range of slope elements, and even the low-permeable parts of the slope will be affected.

We demonstrate in this paper that, depending on the saturation and pressure states in the low permeability zones, the slope deformation magnitude under the same free water-surface movement could vary 10 to $20 \%$. Short and long-period oscillations are superimposed on one another in nature, and the HM effects on a heterogeneous, fractured slope resulting from these oscillations can induce elastic hysteretic effects (and in some cases permanent plastic effects). These effects cause increased strain and damage to pre-existing discontinuities in some areas of the slope (like the low permeable fractured zones), and sometimes local failure.

\subsection{Identification of the main features responsible for fractured porous slope stability}

In the Coaraze case, slope movement is linked to the deformation of two or three vertical faults. Nevertheless, despite the high variability in its elements properties, the global behavior of the slope can be restored, given the slope's simplified structure to a few fractures embedded in a continuous rock matrix. Specifically, assigning equivalent properties to the continuous zones between the selected discontinuities does not greatly improve the model, because more than $90 \%$ of slope movement is linked to deformations in the selected fracture planes, which must remain as explicit elements in the model geometry. This means that in a given complex slope geometry, made of a large number of multiscale fractures with various directional families, only a few high permeable and high deformable fractures are important elements for understanding slope HM response.

Consequently, accurate characterization of slope stability requires construction of a relatively complex model, in which geometric, hydraulic, and mechanical properties of the discontinuities with a large continuity must be carefully determined. For example, in the 
Coaraze case, introducing the bedding-planes into the slope geometrical model is likely required to explain the remaining $10 \%$ of slope movements related to deformation along bedding-planes, where the main part of slope damage occurs through sliding, induced by stress transfers from the vertical faults.

\section{Conclusions and Discussions}

Combining surface tilt measurements with localized internal coupled pressure/deformation measurements appears to be an effective method for characterizing damage and monitoring fractured-porous slope stability. Given a slope geometry that can be characterized with other methods, such as geological mapping and geophysical imaging, tiltmeter monitoring of slope surface movements allows us to localize the highly deformable and permeable discontinuities that cause slope movements. Indeed, as in the case of monitoring fluid displacements in ground reservoir production, tiltmeters appear capable of identifying or tracking the fast emptying of highly deformable discontinuities in a slope. Internal coupled pressure/deformation measurements enable us to estimate the hydromechanical properties of the discontinuities and to calibrate the analysis of tiltmeter signals with a fully coupled hydromechanical numerical model.

Furthermore, change in the tilt signal over time could be a good indication of change in the slope HM properties linked to progressive failure propagation. Indeed, when Mohr-Coulomb material behavior is introduced into the model, surface tilt clearly appears to be sensitive to failure located along short segments of the discontinuities. Thus, permanent monitoring of infinitesimal land-surface rotations might be a good way to follow progressive damage of the slope, long before any large failure occurs. It would also lead to a more complete characterization of slope deformation tensor since mainly translational slope displacements and deformations are currently monitored through remote sensing or EDM methods, and through inclinometers used to monitor failure surface evolution in deep boreholes.

This proposed method-based on combining surface tilt measurements with localized internal coupled pressure/deformation measurements-raises some questions. The first question is how many tiltmeters need to be installed on the slope to capture representative slope deformation behavior? Setting tiltmeters on the slope is a very simple and low-cost procedure, because these devices can easily be moved from point to point to investigate very large slopes. In our experience, an array of 5 to 10 bidirectional tiltmeters would be necessary to adequately characterize a complex slope of hectometric dimensions. Loading tests can involve an artificial air- or water-injection test performed in a borehole located in the basal, saturated part of the slope. The next question is what are the 3D effects in slope deformation processes? Those effects were observed in slope tilt and they almost certainly influence slope stability, and they have to be studied through 3D models in those parts of the slope were they are predominant. The last question is that only normal stiffness was currently correlated to fractures permeability. What about the shear stiffness? Indeed, in our analyses, shear stiffness was estimated to be one tenth of the normal stiffness but the devices did not allow measuring shear displacements. Since most of the damage along bedding-planes could be related to sliding along those planes, there is an urgent need to improve this approach through the development of in situ measurements of both normal and shear displacements of fractures walls. 


\section{References}

[1] Erisman T, Abele G. Dynamics of rockslides and rockfalls. Springer Verlag, Berlin, $200 ; 316$.

[2] Sartori M, Baillifard F, Jaboyedoff M, Rouiller J.D. Kinematics of the 1991 Randa rockslides (Valais, Swizerland). Natural Hazards and Earth Systems Sciences, 2003;3:423433.

[3] Cappa F, Guglielmi Y, Merrien-Soukatchoff V, Mudry J, Bertrand C, Charmoille A. Hydrochemical modeling of a large moving rock slope inferred from slope levelling coupled to spring long-term hydrochemical monitoring: example of the La Clapière landslide (Southern Alps, France). J Hydrol, 2004;291:67-90

[4] Tsang YW, Witherspoon PA. Hydromechanical Behavior of a Deformable Rock Fracture Subject to Normal Stress. J Geophys Res, 1981; 86:9287-9298.

[5] Bandis SC, Lumsden AC, Barton N. Fundamentals of Rock joint Deformation. Int J Rock Mech Min Sci \& Geomech Abstr 1983;20:249-268.

[6] Raven KG, Gale JE. Water flow in a natural rock fracture as a function of stress and sample size. Int J Rock Mech Min Sci, 1985;22:251-261.

[7] Rutqvist J, Stephansson O. The role of hydromechanical coupling in fractured rock engineering. Hydrogeology Journal, 2003;11:7-40.

[8] Cook NGW. Natural Joints in Rock: Mechanical, Hydraulic and Seismic Behavior and Properties under Normal Stress. In: Jaeger Memorial Didaction Lecture, Int J Rock Mech Min Sci \& Geomech Abstr, 1992;29:198-223.

[9] Gale J. A numerical, field and laboratory study of flow in rock with deformable fractures. PhD Thesis, University of California, Berkeley, 1975.

[10] Henry JP, Sibai M. Couplage hydromécanique dans les joints rocheux sous sollicitations normales: proposition de modélisation et comparaison avec l'expérience. Expérimentation et Calcul en Génie Civil, 1997;47-54.

[11] Hopkins DL. The Implications of Joint Deformation in Analyzing the Properties and Behavior of Fractured Rock Masses, Underground Excavations and Faults. Int J Rock Mech Min Sci, 2000;37:175-202.

[12] Pyrak-Nolte LJ, Morris JP. Single fractures under normal stress: the relation between fracture specific stiffness and fluid flow. Int J Rock Mech Min Sci, 2000;37:245-262.

[13] Makurat A, Barton N, Rad NS. Joint conductivity variation due to normal and shear deformation. In: Barton N, Stephansson O (eds) Rock Joints: Balkema, Rotterdam, 1991, pp. 535-540.

[14] Olsson R, Barton N. An improved model for hydromechanical coupling during shearing of rock joints. Int J Rock Mech Min Sci, 2001;38:317-329. 
[15] Myer LR. Hydromechanical and seismic properties of fractures. In: Wittke W (eds) Proc. 7th Int. Congr. Rock. Mechanics. Aachen, Germany. Ed. Balkema, Rotterdam, 1991,pp. 397404.

[16] Cornet FH., Morin RH. Evaluation of hydromechanical coupling in a granite rock mass from a high-volume high-pressure injection experiment: Le Mayet de Montagne, France. Int J Rock Mech Min Sci \& Geomech Abstr, 1997;34 paper n²07.

[17] Rutqvist J. Coupled stress-flow properties of rock joints from hydraulic field testing. $\mathrm{PhD}$ Thesis, Royal Institute of Technology, Sweden, 1995a.

[18] Rutqvist J. Determination of hydraulic normal stiffness of fractures in hard rock from well testing. Int J Rock Mech Min Sci \& Geomech Abs,1995b;32:513-523.

[19] Doe TW, Korbin GE. A comparison of hydraulic fracturing and hydraulic jacking stress measurements. $28^{\text {th }}$ US Symposium on Rock Mechanics, Tucson, 1987.

[20] Cappa F, Guglielmi Y, Rutqvist J, Tsang CF, Thoraval A. Hydromechanical modeling of pulse tests that measure both fluid pressure and fracture-normal displacement at Coaraze Laboratory Site, France. Int J Rock Mech Min Sci, 2006;43:1062-1082.

[21] Gertsch LS. Changes in in situ rock joint flow characteristics caused by mechanical displacement. In: Rocks Mechanics Contributions and Challenges, ed. Hustrulid and Johnson, 1990; pp. 363-370.

[22] Cappa F, Guglielmi Y, Fénart P, Merrien-Soukatchoff V, Thoraval A. Hydromechanical interactions in a fractured carbonate reservoir inferred from hydraulic and mechanical measurements. Int J Rock Mech Min Sci, 2005;42:287-306.

[23] Wang HF. Theory of linear poroelasticity. Princeton University Press, 41 William street, Princeton, New Jersey 08540, 2000.

[24] Tsang CF. Linking thermal, hydrological, and mechanical processes fractured rocks. Annu Rev Earth Planet Sci,1999;27:359-384.

[25] Murdoch LC, Schweisinger T, Svenson E And Germanovich L. Measuring and analysing transient changes in fracture aperture during hydraulic well tests: preliminary results. In: Second International Symposium on Dynamics of Fluids in Fractured Rock, Berkeley, CA, 2004; pp. 129-132.

[26] Bonzanigo L, Eberhardt E, Loew S. Hydromechanical factors controlling the creeping Campo Vallemaggia Landslide. In: Proceedings Landslides - Causes, Impacts and Countermeasures, Davos, Switzerland, 2001; pp. 13-22.

[27] Eberhardt E, Stead D, Coggan JS. Numerical analysis of initiation and progressive failure in natural rock slopes - the 1991 Randa rockslide. Int J Rock Mech Min Sci, 2004;41, 69-87.

[28] Hoek E, Brown ET. Empirical strength criterion for rock masses. In: Journal of the Geotechnical engineering Division, ed. ASCE, 1980, 106(n $\left.{ }^{\circ} \mathrm{GT} 9\right)$, pp. 1013-1035. 
[29] Sjöberg J. Analysis of large scale rock slopes. Doctoral thesis, Department of Civil Engineering - Division of Rock Mechanics, ISSN:1402 - 1544, ISRN:LTU-DT_99/1, 1999; $682 \mathrm{p}$.

[30] Amadei B. Importance of anisotropy when estimating and measuring in situ stresses in rock. Int J Rock Mech Min Sci \& Geomech Abstr, 1996; 33(3):293-325.

[31] Finlayson B, Statham I. Hillslope analysis. London: Heinemann, 1980.

[32] Noverraz F, Bonnard C, Dupraz H, Huguenin L. Grands glissements de versants et climat. Rapport final PNR 31, vdf hochschulverlag AG an der ETH Zürich, 1998, 314 p.

[33] Keeble AB. Freeze-thaw cycles and rock weathering in Alberta. Albertan Geographer, $1971 ; 34-42$.

[34] Biot M.A. General theory of three-dimensional consolidation. Appl Phys, 1941;12:144164.

[35] Terzaghi K. Die Berechning der Durchlässigkeitziffer des Tonesaus dem Verlauf Spannungserscheinungen, Akad. Der Wissenchafen in Wien, Sitzungsberichte, Mathematischnaturwissenschafttliche Klasse, Part Iia, 142(3/4), 1923;125-138.

[36] Tang CA, Tham LG, Lee PKK, Yang TH, Li LC. Coupled analysis of flow, stress and damage (FSD) in rock failure. Int J Rock Mec. Min Sci \& Geomech Abs, 2002;39(4):477-489.

[37] Tsao TM, Wang MK, Chen MC, Takeuchi Y, Matsura S, Ochiai H. A case study of the pore water pressure fluctuation on the slip surface using horizontal borehole works on drainage well. Eng Geol, 2005;78(1-2):105-138.

[38] Clow DW, Drever JI. Weathering rates as a function of flow through an alpine soil. Chemical Geology, 1996;132:131.

[39] Furuya G, Sassa K, Hiura H, Fukuoka H. Mechanism of creep movement caused by landslide activity and underground erosion in crystalline schist, Shikoku Island, southwestern Japan. Eng Geol, 1999;53(3-4):311-325.

[40] Gardner R. ,Walsh N. Chemical weathering of metamorphic rocks from low elevations in the southern Himalaya. Chemical Geology, 1996;127(1-3):161-176.

[41] Wen BP, Duzgoren-Aydin NS, Aydin A. Geochemical characteristics of the slip zones of a landslide in granitic saprolite, Hong-Kong: implications for their development and microenvironments. Environmental Geology, 2004;47(1):140-176.

[42] Guglielmi Y. Hydromechanics of fractured rock masses: Results from an experimental site in limestone. In: Mechanics of jointed and faulted rock, ed. Rossmanith H-P.: A.A. Balkema, Rotterdam, 1998; pp. 621-624.

[43] Fénart P. Caractérisation du comportement hydromécanique des massifs rocheux fissurés. PhD Thesis, University of Montpellier II, 2002; 308 p. 
[44] Kadiri I. Modélisation hydromécanique des milieux fracturés, PhD Thesis, INPL, Nancy, $2002 ; 143 p$

[45] Noorishad J, Tsang CF, Witherspoon PA. Theoretical and field studies of coupled hydromechanical behavior of fractured rocks - 1. Development and verification of a numerical simulator. Int J Rock Mech Min Sci \& Geomech Abstr, 1992;29:401-409.

[46] Itasca Consulting Group, FLAC ${ }^{3 D}$, Fast Lagrangian Analysis of Continua in 3 Dimensions. Version 2.0. Five volumes. Minneapolis, Minnesota: Itasca Consulting Group, 1997.

[47] Cundall PA. Formulation of a three-dimensional distinct element model-Part I. A scheme to detect and represent contacts in a system composed of many polyhedral blocks. Int J Rock Mech Min Sci \& Geomech Abstr, 1988;25:107-116.

[48] Zimmerman RW, Bodvarsson GS. Hydraulic conductivity of rock fractures. Transp Porous Media, 1996;23:1-30.

[49] Guglielmi Y, Cappa F, Binet S. 2005 - Coupling between hydrogeology and deformation of mountainous rock slopes: Insights of La Clapière area (Southern-Alps, France). C. R. Géosciences, 2005;337:1154-1163

[50] Maréchal JC. Les circulations d'eau dans les massifs cristallins alpins et leurs relations avec les ouvrages souterrains. PhD thesis, 1769, EPF, Lausanne, 1998;298 p.

[51] Frayssines M. Contribution à l'évaluation de l'aléa éboulement rocheux. Phd thesis, University Joseph Fourrier Grenoble 1, 2005; 218 p. 


\section{Figure captions:}

Figure 1: Coaraze Laboratory site: (a) three-dimensional view of large-continuity fractures with the location of tiltmeters; (b) vertical cross sections with a schematic image of slope fracturation and the location of sensors; (c) pole plots showing brittle faults and bedding-plane orientations (lower hemisphere); (d) coupled pressure-deformation measuring point; (e) surface tiltmeter.

Figure 2: Pressure (left axis) and deformation (right axis) variations with time measured at different locations in faults, bedding-planes, rock matrix, and at land surface.

Figure 3: Numerical continuum (ROCMAS, FLAC ${ }^{3 \mathrm{D}}$ ) and discontinuum (UDEC) models geometries.

Figure 4: Comparison between measured and calculated pressure, deformation and tilt; 1 experimental data; 2 - undifferentiated models; 3 - UDEC; 4 - ROCMAS; 5 - FLAC3D.

Figure 5: Modeled pressures ( $\mathrm{a}$ - pressure at 2,000 seconds, $\mathrm{b}$ - pressure at 7,200 seconds) and displacement fields (c- displacements at 2,000 seconds, d - displacements at 7,200 seconds).

Figure 6: Influence of fractures with a decametric continuity on slope movements.

Figure 7: Sensitivity study of how the hydraulic properties of slope elements affect slope HM behavior.

Figure 8: Sensitivity study of how the mechanical properties of slope elements affect slope HM behavior.

Figure 9: Sensitivity study of loading/unloading periodicity and of constitutive laws for slope HM behavior.

Figure 10: Synthesis of HM effects in a fractured rock slope: (a) correlation between hydraulic permeability and normal stiffness of slope discontinuities; (b) localization of damage in the slope related to slope geometry and displacement field induced by a water level movement.

Table 1: Material properties affected in the best fit simulations

Table 2: Synthesis of sensitivity study results 


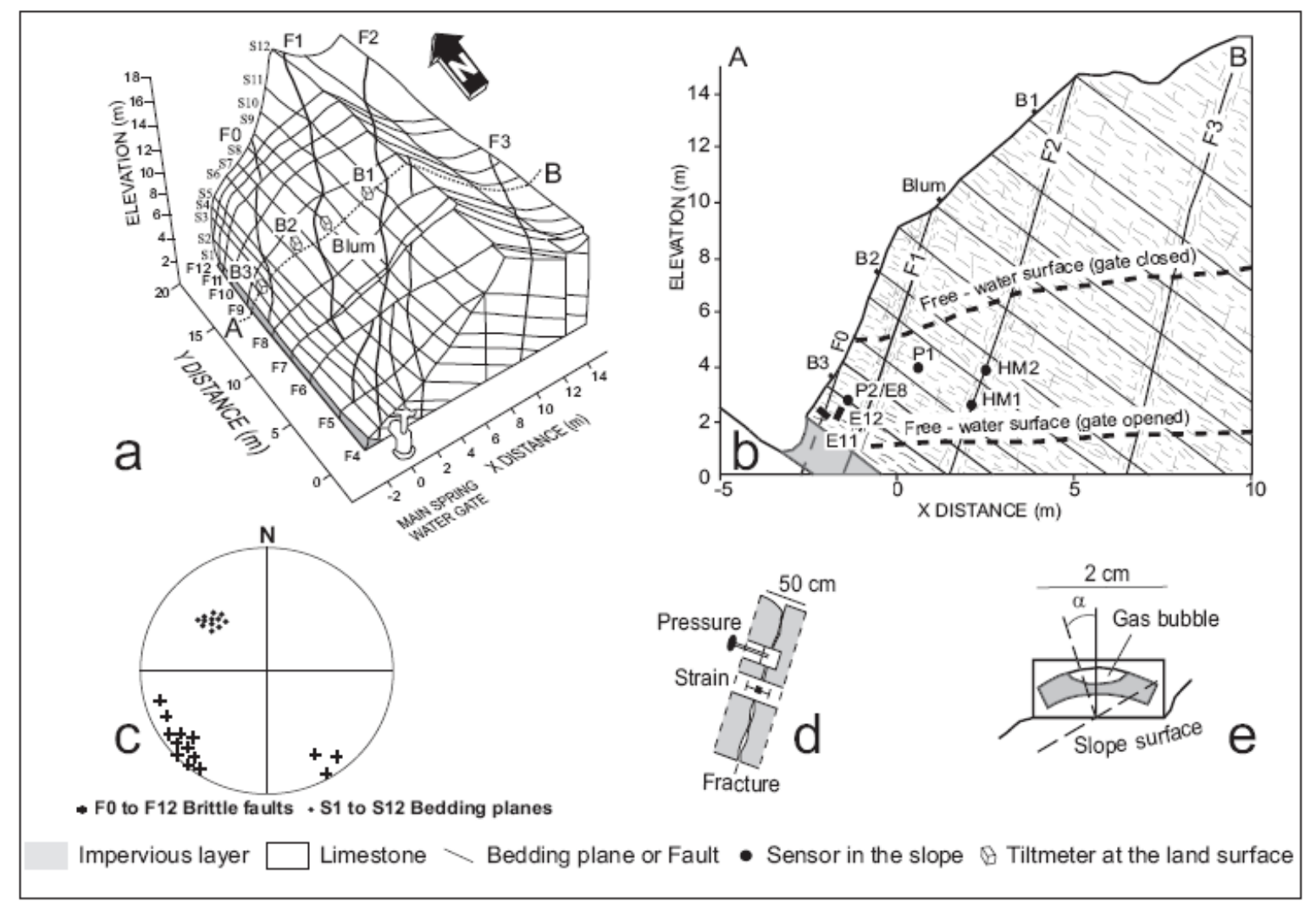

Fig. 1 


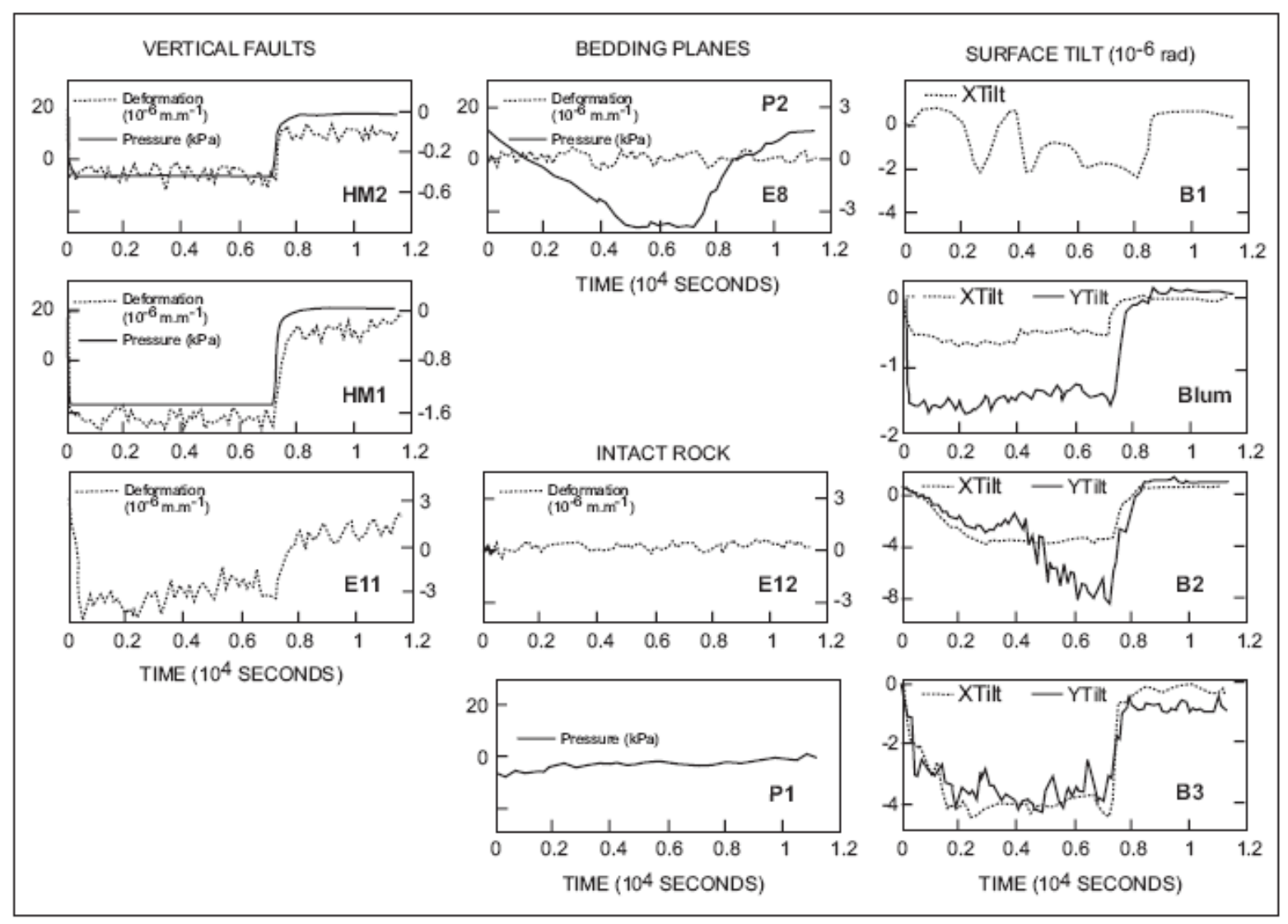

Fig. 2 


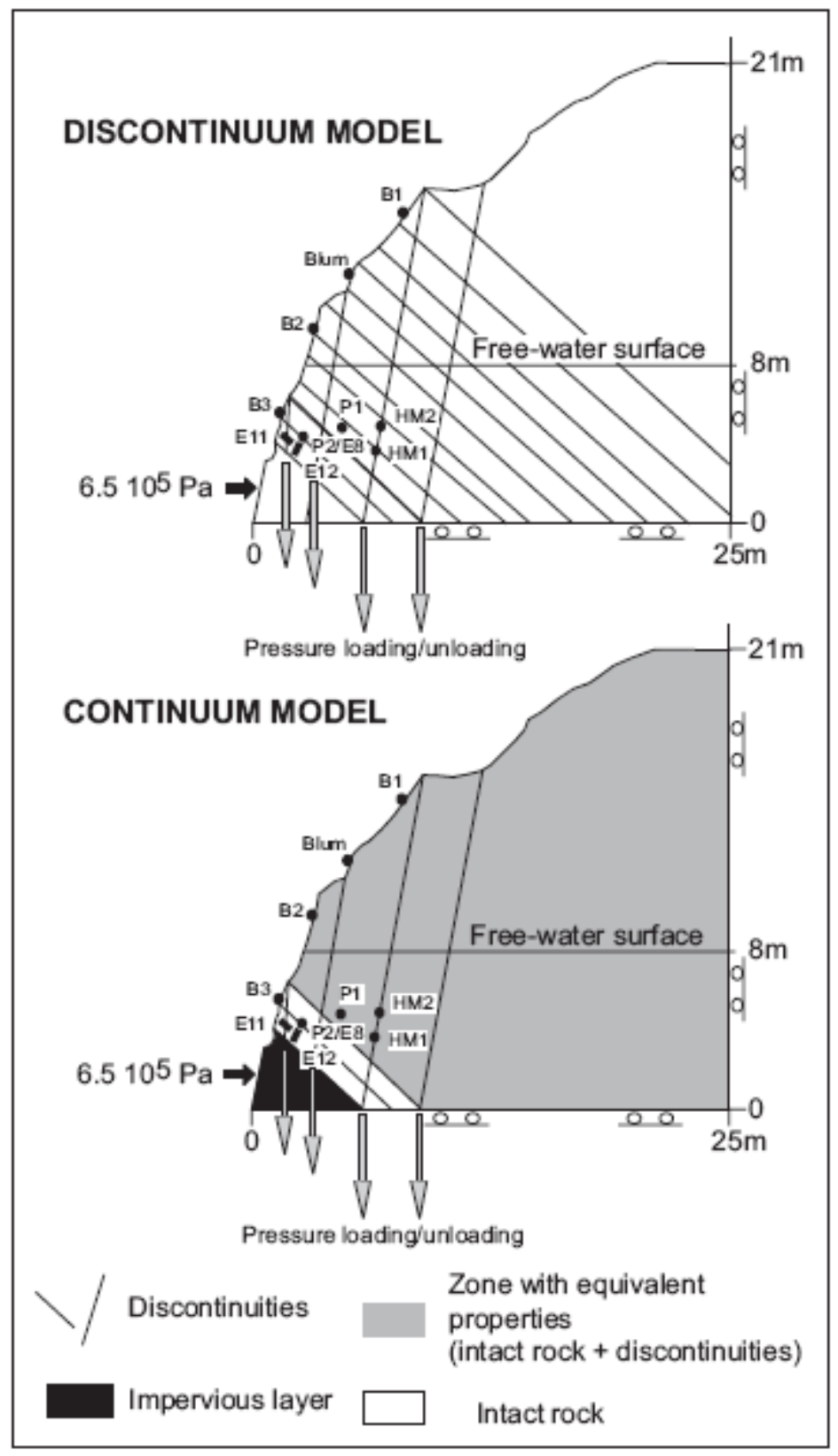

Fig. 3 


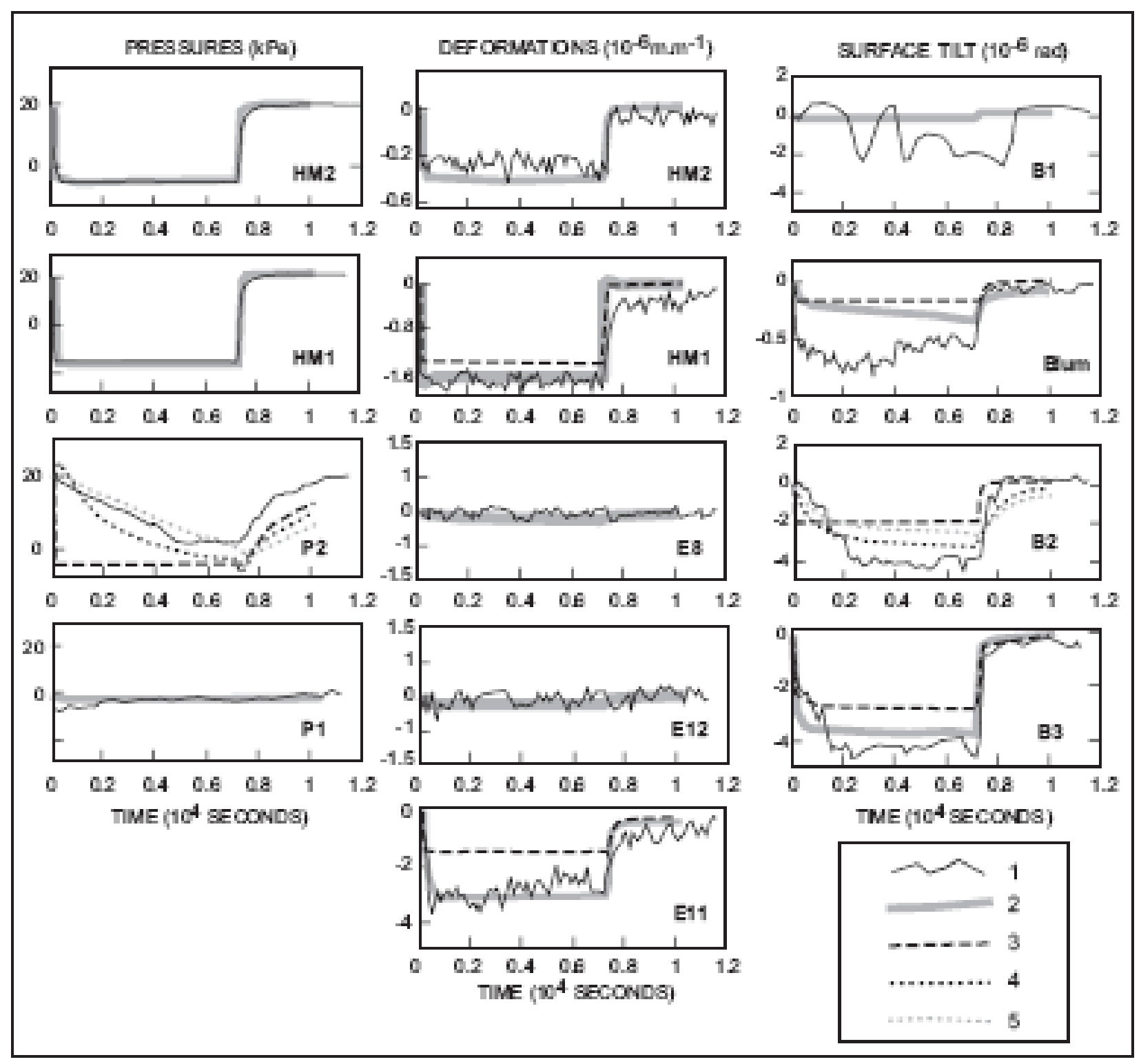

Fig. 4 


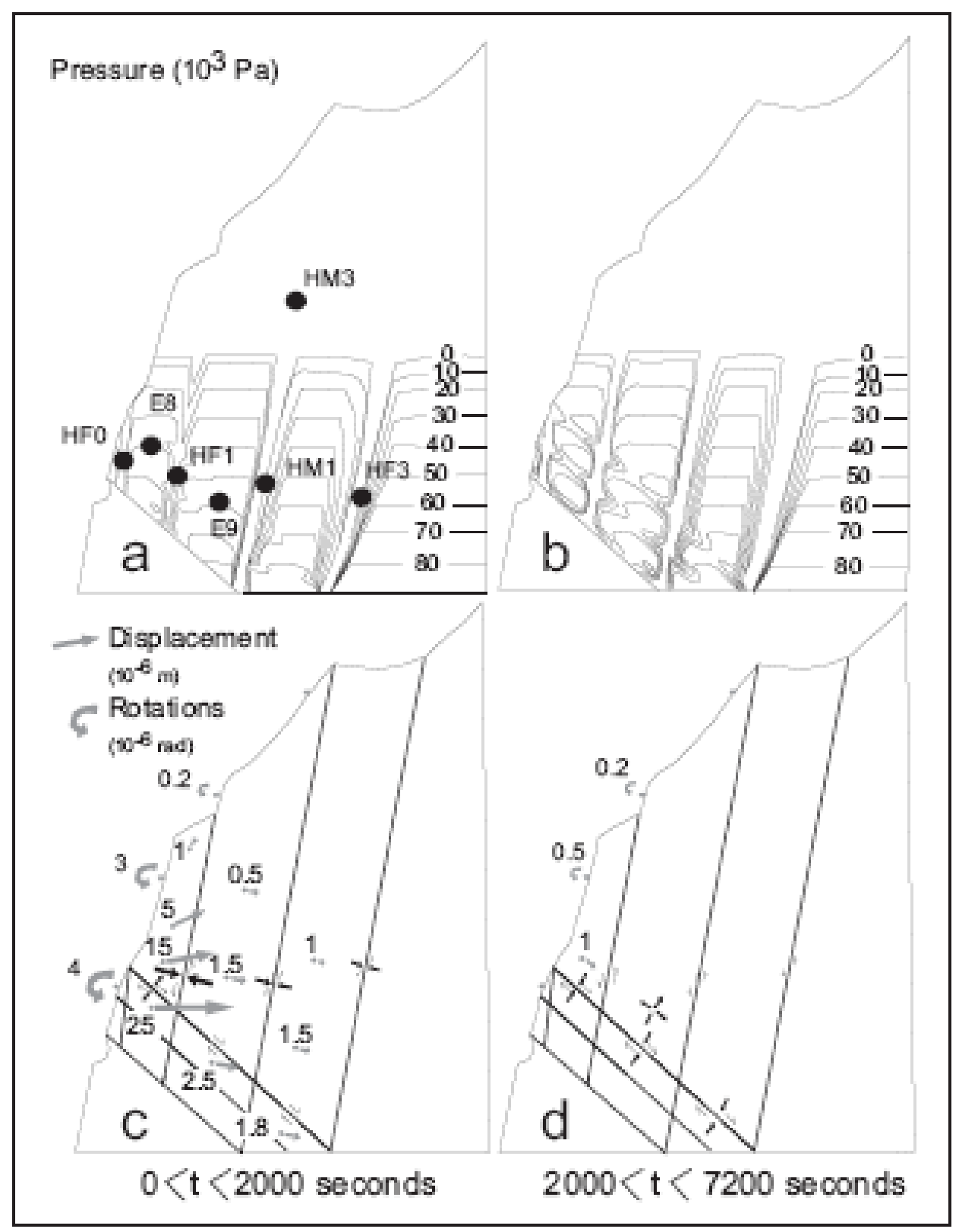

Fig. 5 


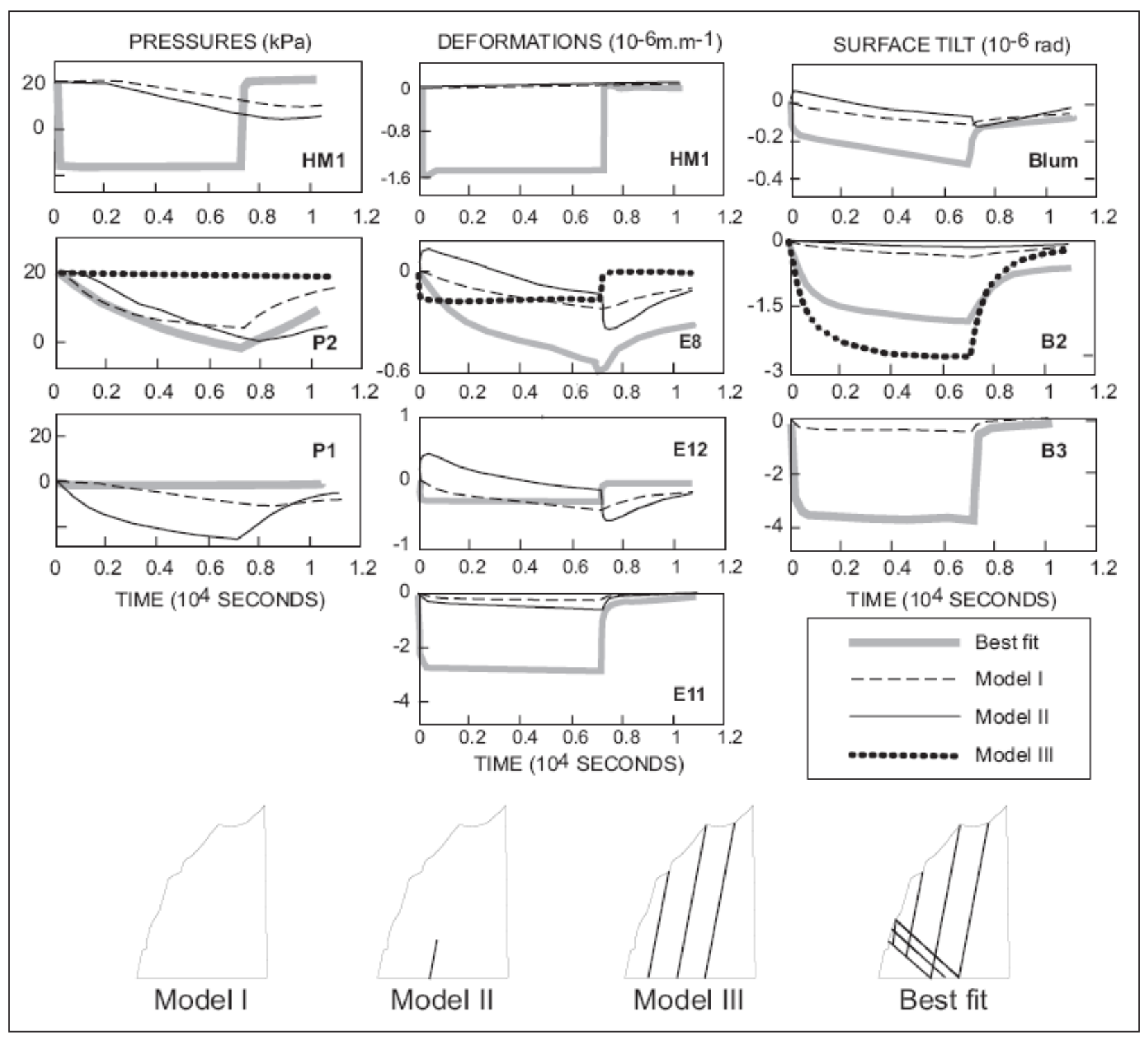

Fig. 6 


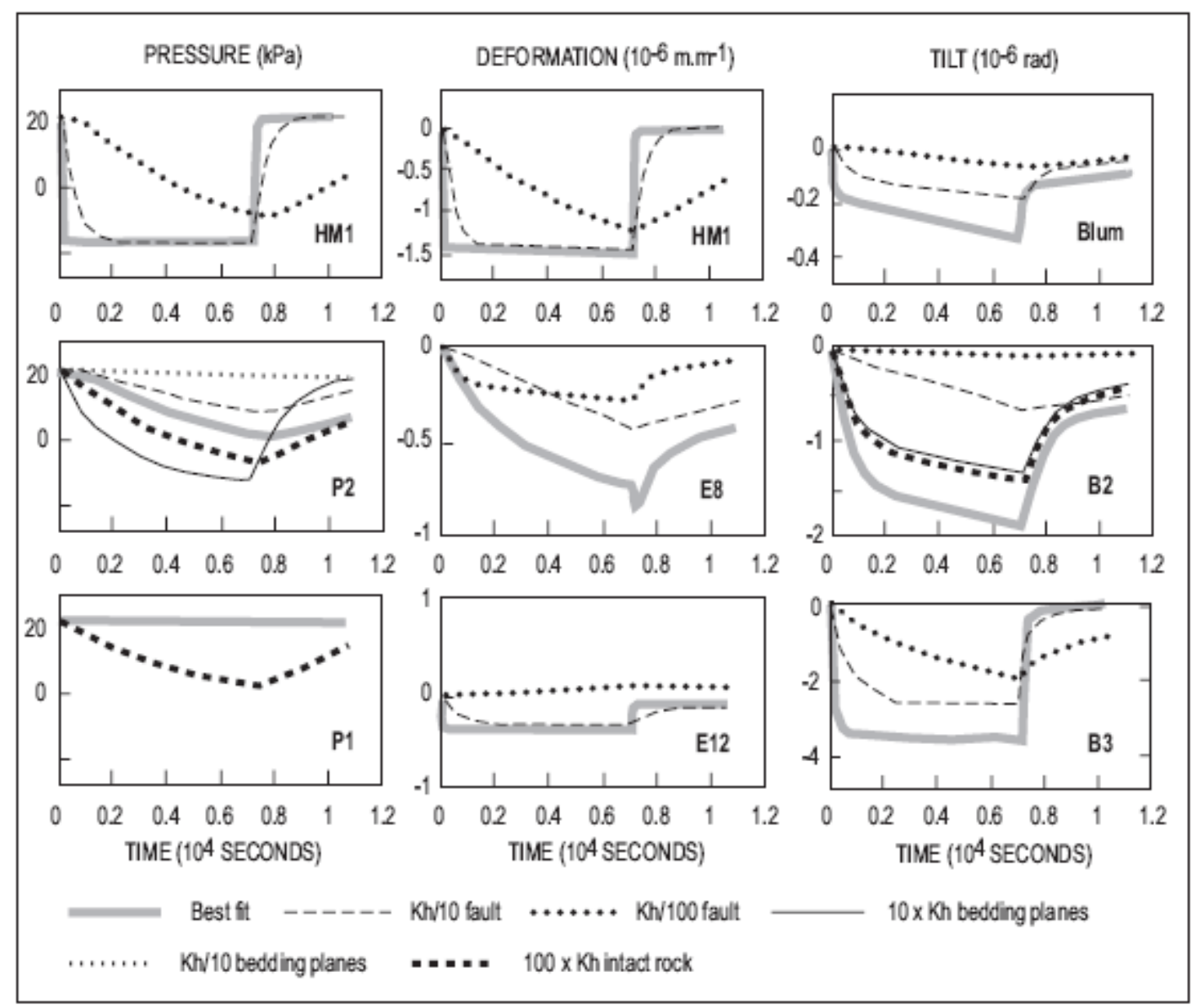

Fig. 7 


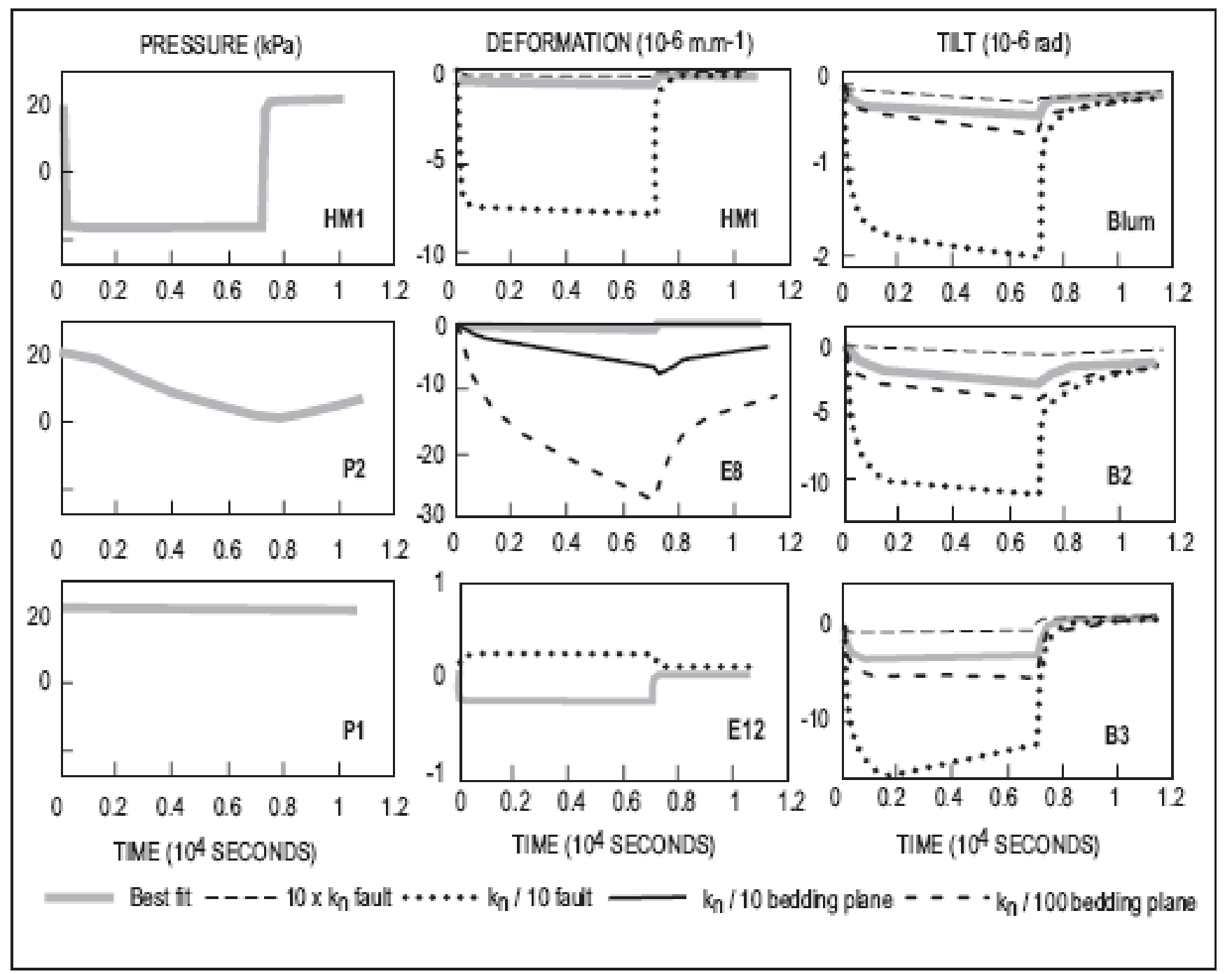

Fig. 8 


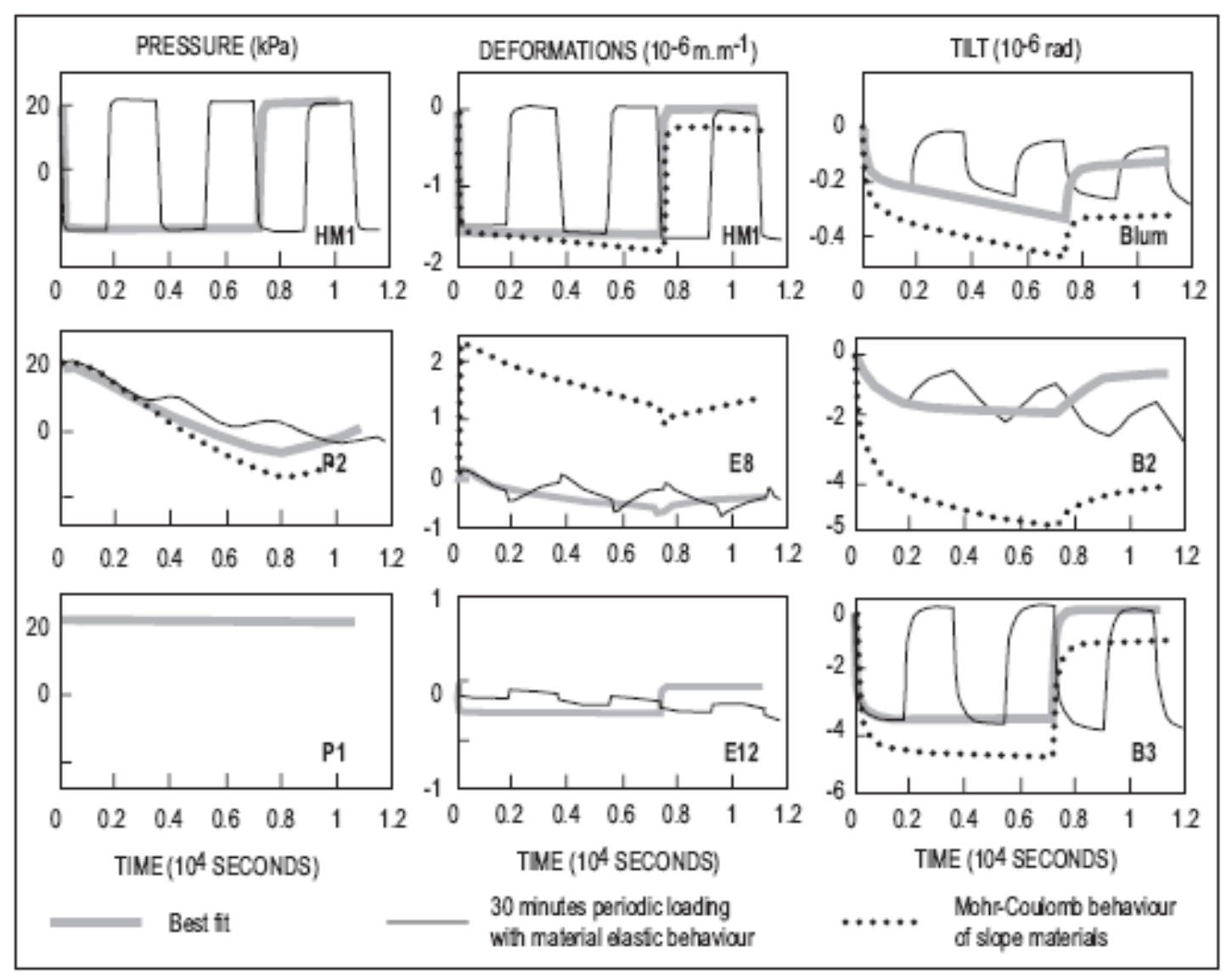

Fig. 9 


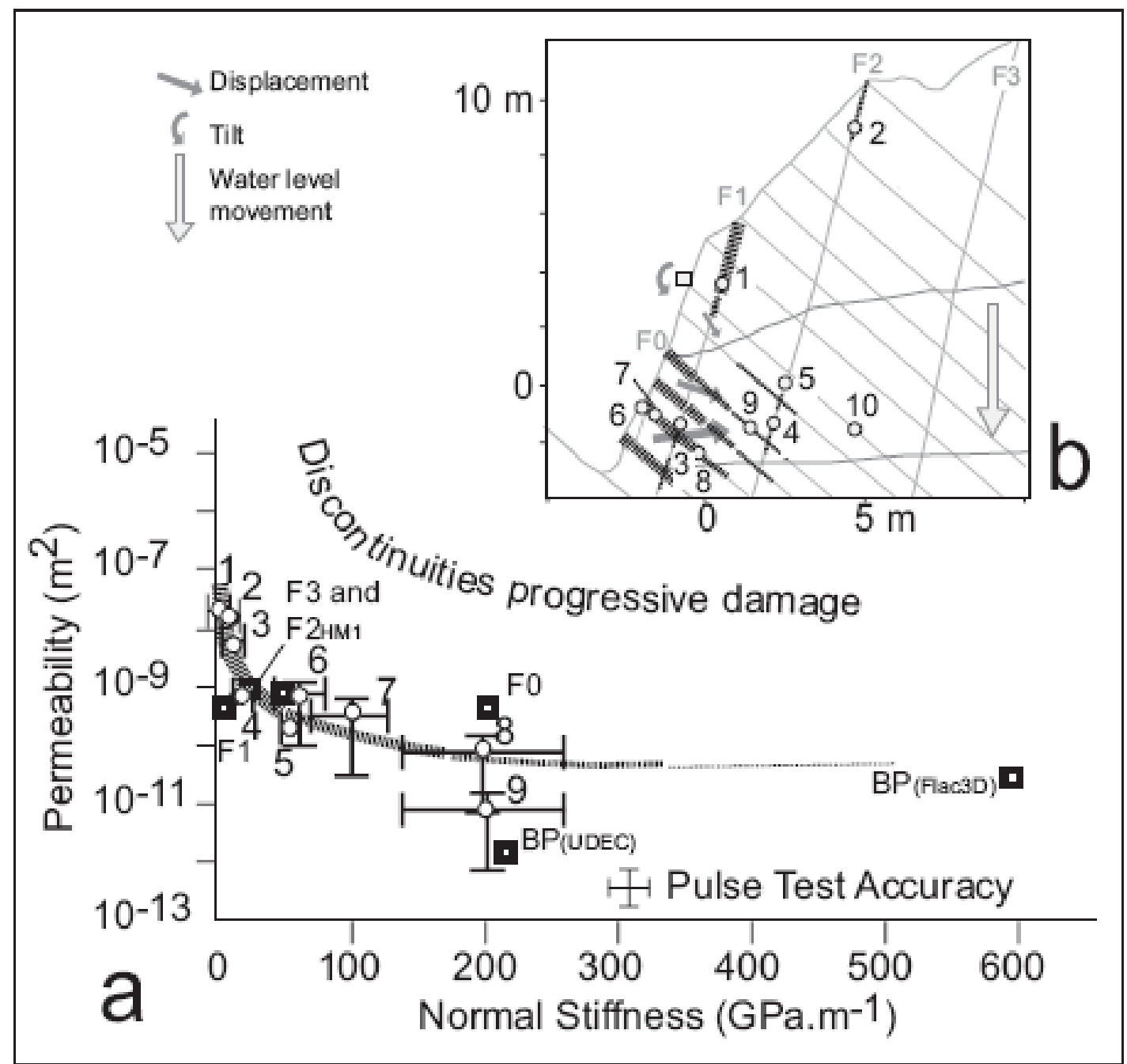

Fig. 10 


\begin{tabular}{lll}
\hline Material & Parameter & Value \\
\hline \multirow{3}{*}{ Impervious basal layer } & Young's modulus, $\mathrm{E}_{\mathrm{R}}(\mathrm{GPa})$ & 68 \\
& Poisson's ratio, $v(-)$ & 0.29 \\
& Mass density, $\rho\left(\mathrm{kg} / \mathrm{m}^{3}\right)$ & 2400 \\
\hline \multirow{4}{*}{ "intact rock" matrix } & Young's modulus, $\mathrm{E}_{\mathrm{R}}(\mathrm{GPa})$ & 68 \\
& Poisson's ratio, $v(-)$ & 0.29 \\
& Mass density, $\rho\left(\mathrm{kg} / \mathrm{m}^{3}\right)$ & 2400 \\
& Porosity, $\mathrm{n}(-)$ & 0.02 to 0.05 \\
& Permeablity, $\mathrm{K}_{\mathrm{h}}\left(\mathrm{m}^{2}\right)$ & $9.8 \times 10^{-17}$ \\
\hline \multirow{3}{*}{ Matrix with mechanical equivalent } & Young's modulus, $\mathrm{E}_{\mathrm{R}}(\mathrm{GPa})$ & 50 \\
& Poisson's ratio, $v(-)$ & 0.29 \\
& Mass density, $\rho\left(\mathrm{kg} / \mathrm{m}^{3}\right)$ & 2400 \\
& Porosity, $\mathrm{n}(-)$ & 0.05 \\
& Permeablity, $\mathrm{K}_{\mathrm{h}}\left(\mathrm{m}^{2}\right)$ & $9.8 \times 10^{-17}$ \\
\hline \multirow{3}{*}{ Faults } & Normal stiffness, $\mathrm{k}_{\mathrm{n}}(\mathrm{GPa} / \mathrm{m})$ & 0.8 to $1.6(\mathrm{~F} 1)$, \\
& & 22 to $50(\mathrm{~F} 2, \mathrm{~F} 0), 22$ \\
& & $(\mathrm{~F} 3)$ \\
& Shear stiffness, $\mathrm{k}_{\mathrm{s}}(\mathrm{GPa} / \mathrm{m})$ & 0.08 to $0.16(\mathrm{~F} 1), 2.2$ to \\
& & $5(\mathrm{~F} 2), 2.2(\mathrm{~F} 3)$ \\
& Hydraulic conductivity $\left(\mathrm{m}^{2}\right)$ & $4.9 \times 10^{-9}(\mathrm{~F} 1, \mathrm{~F} 0), 9.8$ \\
& & $\times 10^{-9}(\mathrm{~F} 2), 9.8 \times 10^{-9}$ \\
& & $(\mathrm{~F} 3)$ \\
\hline \multirow{2}{*}{ Bedding-planes } & Normal stiffness, $\mathrm{k}_{\mathrm{n}}(\mathrm{GPa} / \mathrm{m})$ & 200 to 600 \\
& Shear stiffness, $\mathrm{k}_{\mathrm{s}}(\mathrm{GPa} / \mathrm{m})$ & 120 \\
& Hydraulic conductivity $\left(\mathrm{m}^{2}\right)$ & $9.8 \times 10^{-11}$ \\
\hline
\end{tabular}

Table 1 


\begin{tabular}{|c|c|c|}
\hline \multicolumn{2}{|c|}{ Tested parameters } & \multirow{2}{*}{$\begin{array}{l}\text { Effects on slope deformation } \\
\text { Compared to best fit slope results } \\
\begin{array}{l}\text { Strong under-estimation of pressure and } \\
\text { deformation variations }\end{array}\end{array}$} \\
\hline \multirow[t]{3}{*}{ Slope heterogeneity } & $\begin{array}{l}\text { Model 1: } \\
\text { Homogeneous slope }\end{array}$ & \\
\hline & $\begin{array}{l}\text { Model II : Slope with } \\
\text { only one short segment } \\
\text { of fault F1 }\end{array}$ & $\begin{array}{l}\text { Local concentration of drainage and } \\
\text { deformation on the fault segment } \\
\text { General under-estimation of slope HM } \\
\text { behavior }\end{array}$ \\
\hline & $\begin{array}{l}\text { Model III : Slope with } \\
3 \text { vertical faults }\end{array}$ & $\begin{array}{l}10 \% \text { underestimation of general behavior } \\
\text { as best fit slope model with all the } \\
\text { elements Figured. } \\
\text { Local HM behavior of elements, mainly } \\
\text { bedding-planes is modified }\end{array}$ \\
\hline \multirow[t]{6}{*}{ Material properties } & Fault permeability & $\begin{array}{l}\text { Complete modification of general and } \\
\text { local slope HM behaviors }\end{array}$ \\
\hline & Fault stiffness & $\begin{array}{l}\text { Complete modification of general and } \\
\text { local slope HM behaviors }\end{array}$ \\
\hline & $\begin{array}{l}\text { Bedding-plane } \\
\text { permeability }\end{array}$ & $\begin{array}{l}\text { Local modification of pressure variation } \\
\text { in bedding-planes and } 10 \% \text { modification } \\
\text { of tilt in the middle part of the slope }\end{array}$ \\
\hline & Bedding-plane stiffness & $\begin{array}{l}\text { Local modification of deformation } \\
\text { variation in bedding-planes and } 10 \% \\
\text { modification of tilt in the middle part of } \\
\text { the slope }\end{array}$ \\
\hline & Matrix permeability & $\begin{array}{l}\text { Pressure variation in matrix but no effect } \\
\text { on HM slope behavior }\end{array}$ \\
\hline & Matrix stiffness & No effect in the range of values tested \\
\hline \multirow[t]{2}{*}{ Constitutive laws } & Elastic behavior & $\begin{array}{l}\text { Predominant effect of low stiff faults } \\
\text { (90\% of slope movements explained) }\end{array}$ \\
\hline & $\begin{array}{l}\text { Mohr-Coulomb } \\
\text { behavior }\end{array}$ & $\begin{array}{l}\text { Shear in bedding-planes influence fault } \\
\text { and general slope deformation }\end{array}$ \\
\hline $\begin{array}{l}\text { Free water-aurface } \\
\text { movements }\end{array}$ & Periodic & $\begin{array}{l}\text { Pressure and strain accumulation in low } \\
\text { permeable bedding-planes induces an } \\
\text { additional general slope deformation }\end{array}$ \\
\hline
\end{tabular}

Table 2 